\title{
Gray matter alterations in early aging: A diffusion magnetic resonance imaging study
}

\section{Citation}

Rathi, Y., O. Pasternak, P. Savadjiev, O. Michailovich, S. Bouix, M. Kubicki, C.-F. Westin, N. Makris, and M.E. Shenton. 2013. "Gray Matter Alterations in Early Aging: A Diffusion Magnetic Resonance Imaging Study." Hum. Brain Mapp. 35 (8) (December 31): 3841-3856. doi:10.1002/ hbm.22441.

\section{Published Version}

doi:10.1002/hbm.22441

\section{Permanent link}

http://nrs.harvard.edu/urn-3:HUL.InstRepos:28539563

\section{Terms of Use}

This article was downloaded from Harvard University's DASH repository, and is made available under the terms and conditions applicable to Other Posted Material, as set forth at http:// nrs.harvard.edu/urn-3:HUL.InstRepos:dash.current.terms-of-use\#LAA

\section{Share Your Story}

The Harvard community has made this article openly available.

Please share how this access benefits you. Submit a story.

\section{Accessibility}




\title{
Gray Matter Alterations in Early Aging: A Diffusion Magnetic Resonance Imaging Study
}

\author{
Y. Rathi ${ }^{1}{ }^{,}$, O. Pasternak ${ }^{1}$, P. Savadjiev ${ }^{1}$, O. Michailovich ${ }^{2}$, S. Bouix ${ }^{1}$, M. Kubicki $^{1}$, C.-F. \\ Westin $^{1}$, N. Makris ${ }^{3}$, and M.E. Shenton ${ }^{1}$ \\ ${ }^{1}$ Brigham and Women's Hospital, Harvard Medical School, Boston, Massachusetts \\ 2University of Waterloo, Canada \\ ${ }^{3}$ Massachusetts General Hospital, Harvard Medical School, Boston, Massachusetts
}

\begin{abstract}
Many studies have observed altered neurofunctional and structural organization in the aging brain. These observations from functional neuroimaging studies show a shift in brain activity from the posterior to the anterior regions with aging (PASA model), as well as a decrease in cortical thickness, which is more pronounced in the frontal lobe followed by the parietal, occipital, and temporal lobes (retrogenesis model). However, very little work has been done using diffusion MRI (dMRI) with respect to examining the structural tissue alterations underlying these neurofunctional changes in the gray matter. Thus, for the first time, we propose to examine gray matter changes using diffusion MRI in the context of aging. In this work, we propose a novel dMRI based measure of gray matter "heterogeneity" that elucidates these functional and structural models (PASA and retrogenesis) of aging from the viewpoint of diffusion MRI. In a cohort of 85 subjects (all males, ages 15-55 years), we show very high correlation between age and "heterogeneity" (a measure of structural layout of tissue in a region-of-interest) in specific brain regions. We examine gray matter alterations by grouping brain regions into anatomical lobes as well as functional zones. Our findings from dMRI data connects the functional and structural domains and confirms the "retrogenesis" hypothesis of gray matter alterations while lending support to the neurofunctional PASA model of aging in addition to showing the preservation of paralimbic areas during healthy aging.
\end{abstract}

\section{Keywords}

diffusion MRI; gray matter; aging; free-water

\section{INTRODUCTION}

Understanding normal human brain development and the processes involved in healthy aging is quite important for understanding the mechanisms behind age related brain

\footnotetext{
(c) 2013 Wiley Periodicals, Inc.

"Correspondence to: Y. Rathi, Brigham and Women's Hospital, Harvard Medical School, Boston, Massachusetts, USA. yogesh@bwh.harvard.edu.
} 
disorders such as Alzheimer's and Parkinson's disease. Several studies on animal models have reported widespread changes in white and gray matter areas of the brain [Bronson et al., 1993; Calderini et al., 1983; Mandybur et al., 1989; Sloane et al., 1999]. Advances in neuroimaging technologies have enabled examining these brain changes in vivo during healthy and pathological aging. In particular, in the last 2 decades, a lot of human studies have used structural MRI (sMRI) to show a decrease in gray matter volume and thickness with age [Allen et al., 2005; Kochunov et al., 2011; Lemaitre et al., 2012; Salat et al., 2004; Sowell et al., 2003; Terribilli et al., 2011]. These measures have been correlated with a decrease in performance on complex tasks in older adults [Sakai et al., 2012; Squarzoni et al., 2012; Steffener et al., 2012].

With the advent of advanced imaging techniques such as functional MRI (fMRI) and diffusion MRI (dMRI), a more detailed picture of the function and anatomy of the brain can be obtained. Specifically, diffusion tensor imaging (DTI) has become an imaging modality of choice for investigating the neural architecture of the brain. It has been extensively used to study white matter changes during brain development and aging [Gunning-Dixon et al., 2009; Madden et al., 2009; Salat et al., 2005; Schulze et al., 2011]. However, its application to cortical gray matter analysis has been limited, with very few studies reporting age related changes using diffusion imaging based measures [Bhagat and Beaulieu, 2004; Pfefferbaum et al., 2010]. Although the first work [Bhagat and Beaulieu, 2004] proposed a CSF (cerebrospinal fluid) suppressed DTI imaging sequence and examined its effect on aging, the second work [Pfefferbaum et al., 2010] analyzed the effect of iron deposition on diffusion measures in sub-cortical regions of older adults. Thus, very little work has been done on analyzing gray matter changes in the various cortical regions (anatomical lobes and functional zones) using diffusion MRI.

Conversely, fMRI, which captures dynamic neural activity in the gray matter based on blood-oxygen level, has been used extensively in aging studies [Nashiro et al., 2012]. Specifically, fMRI is a useful imaging modality that can capture resting state as well as task specific activation of neural processes in the cortical and sub-cortical areas of the brain. As such, it has been widely used to understand the function of various regions of the brain. In particular, several models of aging, namely, HAROLD (hemispheric asymmetry reduction in older adults) and PASA (posterior-to-anterior shift in aging) have been proposed based on fMRI activity patterns analyzed across the lifespan [Cabeza, 2002; Cabeza et al., 2002; Davis et al., 2008; Grady et al., 1994]. These models have also found support from various studies done in the domain of cognitive and behavioral neuroscience [Dolcos et al., 2002; Huettel et al., 2001; Iidaka et al., 2002; Madden et al., 2002]. However, the underlying structural changes in the tissue properties that can explain these phenomena have not been explored.

In this work, we use diffusion MRI to understand the structural gray matter changes in early aging. We use advanced dMRI models that go beyond the standard DTI model, wherein, the diffusion signal is separated into an extracellular and a tissue compartment. We use measures derived from this model to compute a novel measure of gray matter "heterogeneity," which characterizes the variability in tissue structure over a given region of interest (ROI). We hypothesize that this measure of gray matter heterogeneity can provide a 
complementary explanation of the functional models of aging such as PASA. Further, it also lends support to the "preservation of limbic structures" and the "first-in last-out" models observed in structural MRI studies.

\section{MATERIALS AND METHODS}

\section{Diffusion MRI}

The advent of diffusion magnetic resonance imaging (dMRI) has provided the opportunity for non-invasive investigation of the neural architecture of the brain. To begin studying the microstructure of fibers, we need a model to interpret the diffusion-weighted signal. One of the simplest models is the diffusion tensor, which describes a Gaussian estimate of the diffusion orientation and strength at each voxel [Basser and Pierpaoli, 1996]. However, recent works have shown that adding an additional isotropic "free-water" term in the model can better explain the diffusion signal and can also help isolate the signal corresponding to the extracellular space [Panagiotaki et al., 2012; Pasternak et al., 2009; Zhu et al., 2011]. We thus use a single tensor with an isotropic free-water compartment as our model of diffusion as given below:

$$
S(u)=(1-\omega) \exp \left(-b u^{T} D u\right)+\omega \exp \left(-b D_{\text {iso }}\right)
$$

where $S$ is the diffusion signal measured along direction $\mathbf{u}, D$ is the diffusion tensor to be estimated, $D_{\text {iso }}$ is the diffusivity of isotropic free-water compartment known from brain parenchyma to be $0.003 \mathrm{~mm}^{2} / \mathrm{s}$ (which is the typical value for freely diffusing water at body temperature) and $\omega$ is the fraction of the signal corresponding to this free-water compartment. The parameters of this model $(D$ and $\omega)$ are estimated within a regularization framework as given in [Pasternak et al., 2009]. In this manuscript, we refer to $\omega$ as the "freewater" component and FA computed from $D$, as the tissue fractional anisotropy $\left(\mathrm{FA}_{\mathrm{t}}\right)$.

In our estimation procedure, we fix the diffusivity $D_{\text {iso }}$ of the isotropic free-water compartment to be $3 \times 10^{-3} \mathrm{~mm}^{2} / \mathrm{s}$ which is at-least three times larger than the diffusivity of gray matter $\left(0.9 \times 10^{-3} \mathrm{~mm}^{2} / \mathrm{s}\right)$ [Helenius et al., 2002]. Thus, separating the diffusion due to the tissue compartment (gray matter in our case) from the free-water compartment is possible due to the fact that these compartments have very different diffusivity coefficients. Second, we constrain the maximum and the minimum eigenvalue of the diffusion tensor (corresponding to the tissue compartment) leading to a constraint on the fractional contribution of each compartment (please see Eq. (6) in [Pasternak et al., 2009]). This further restricts the plausible range for the solution of the fractional part for each compartment $\left(\omega_{\min }<\omega<\omega_{\max }\right)$. Note that, in this constrained space, one cannot arbitrarily shift weight given to the free-water (FW) part by reducing the weight of the tensor, as the overall diffusivity of the tensor is necessarily less than that of free-water. Further, from the bio-physiology of brain tissue, we know that the overall diffusivity of the tissue compartment should be quite low compared to free-water. We should however mention that minor shifting of the weights $(\omega)$ from one compartment to the other is always a possibility and to account for this, we use a spatial regularization term, which enforces a piece-wise spatially smooth estimate of the anisotropic tensor compartment and consequently that of the FW compartment. Thus, $\omega$ cannot change abruptly from one voxel to the next in a 
neighborhood. Additionally, spatial smoothness ensures that the noise in our estimation is significantly reduced.

Fixing the free-water diffusivity $D_{\text {iso }}$ to a large value $\left(3 \times 10^{-3} \mathrm{~mm}^{2} / \mathrm{s}\right)$ dictates an average molecular displacement in the range of a few tens of microns, that is, the signal originates from water pockets, which in the brain could only appear in the extracellular space or CSF areas [Pasternak et al., 2012b]. This has also been validated using histology in the work of [Wang et al., 2011]. Thus, due to the way our model has been constructed, the free-water compartment represents diffusion in the extracellular space or CSF areas. We should emphasize that this does not imply that the tissue compartment is purely intracellular. Conversely, the signal of the tissue compartment originates from all other water molecules that are hindered or restricted by cellular structures (e.g., membranes and myelin sheaths). These molecules include all of the intracellular molecules and some extracellular molecules that are in proximity to cellular restrictions. Finally, we would like to point out that a better estimate of the extracellular compartment could be obtained only if multiple $b$-value data is available [Pasternak et al., 2012a; Zhang et al., 2012]. In our case, our data were acquired at a single $b$-value and hence the above two-compartment model is best suited for our dataset. We should note that using this isotropic free-water component is also useful in removing CSF contamination due to partial-volume as described in [Metzler-Baddeley et al., 2012].

\section{Heterogeneity: A Measure of Intrinsic Variability}

Existing work using dMRI has traditionally looked at average values of a given measure within a region-of-interest (ROI). Thus, most studies compute average FA or average mean diffusivity (MD) to understand the aging process. However, in ROI-based studies, this may not capture the entire information available about that region. For example, a given ROI in two individuals could have the same "average FA" but vastly different variance. Thus, it is necessary to not only to analyze the average values but also to look into the variability of that measure within the region. We thus propose a measure called "heterogeneity," which can robustly capture the variability of any given diffusion measure (such as $F A_{t}$ ) within a ROI. This measure is less sensitive to outliers than the standard statistical measure of "variance" or "standard deviation" and is mathematically defined as:

$$
H(m)=\frac{1}{N^{2}} \sum_{i=1}^{N} \sum_{j=1}^{N}\left\|m_{i}-m_{j}\right\|
$$

where $N$ is the number of voxels in the ROI, and $m_{\mathrm{i}}$ is the value of any given diffusion measure (such as, $\mathrm{FA}_{t}$ ) indexed by $i$ or $j$. Note that, the measure $H$ does not change based on the order of the indexing scheme (any ordering of $\mathrm{FA}_{\mathrm{t}}$, within a given ROI will give the same value for $H$ ). Further, a "global" change in the value of $\mathrm{FA}_{\mathrm{t}}$, does not change the heterogeneity, that is, increasing or decreasing the value of $\mathrm{FA}_{t}$ by the same amount throughout an ROI will not change heterogeneity of that region. Note that, the unit for $H$ is the same as that of the measure $m$, that is, for $\mathrm{FA}_{\mathrm{t}}$ it is dimensionless, while for mean diffusivity $\left(\mathrm{MD}_{\mathrm{t}}\right)$ it is $\mathrm{mm}^{2} / \mathrm{s}$. In this work, we compute heterogeneity $H$ of the tissue $\mathrm{FA}_{\mathrm{t}}$ (denoted by $\mathrm{HFA}_{t}$ in the rest of this article) within the cortical and subcortical gray matter and discuss its implication in aging. 
Note that, the tissue fractional anisotropy captures the coherence of water diffusion at each voxel. Thus, a higher value of $\mathrm{FA}_{\mathrm{t}}$ would imply high coherence in diffusion along a particular direction, whereas low values for $\mathrm{FA}_{t}$ imply near-isotropic diffusion. Further, a large variation in the tissue structure leads to a large variation in the coherence pattern of diffusion from one location to another, which in turn leads to large variation in the values for $\mathrm{FA}_{t}$ in an ROI. This phenomenon is captured by our measure of heterogeneity. Figure 1 shows a schematic of cell layout that could lead to increased heterogeneity in a given ROI.

\section{Study Participants}

Eighty-five subjects (age range: 15-55 years, 85 males) were recruited from the Boston area, with IQ score greater than 80 . All subjects were primarily right-handed, with an average score of 0.81 on the Annett Handedness Scale, average education of 14.62 years, and an average socioeconomic status (SES) score of 2.12. See Figure 1 for a distribution of the subjects with age. Exclusion criteria for all subjects were: sensory-motor handicaps (e.g., severe visual or auditory problems), apparent psychiatric disorder, seizure disorder, neurosurgical procedures, medical illnesses that significantly impair neurocognitive function (e.g., renal disease), and conditions incompatible with MRI scanning (e.g., certain types of metal in the body, cardiac pacemakers, claustrophobia, and pregnancy). All participants gave written informed consent and the research protocol was approved by the Brigham and Women's Hospital's local Internal Review Board.

\section{MRI Acquisition}

MR images were acquired on a 3-T whole body General Electric MRI scanner (GE Medical Systems, Milwaukee) at Brigham and Women's Hospital. The MR sequences included a high resolution 3D-T1 scan (IR-SPGR, TR $7.8 \mathrm{~ms}$, TE $3 \mathrm{~ms}$, TI $600 \mathrm{~ms}$, flip angle 10 ${ }^{\circ}$, FOV $256 \times 256 \mathrm{~mm}^{2}$, matrix size $256 \times 256,176$ slices, $1 \mathrm{~mm}$ slice thickness), a high resolution 3D-T2 (CUBE, TR $3 \mathrm{~s}$, TE $90 \mathrm{~ms}$, flip angle $90^{\circ}$, FOV $256 \times 256 \mathrm{~mm}^{2}$, matrix size $256 \times$ 256, 176 slices, $1 \mathrm{~mm}$ slice thickness), and a high resolution diffusion acquisition (twice refocused, TR $17 \mathrm{~s}, \mathrm{TE}=80 \mathrm{~ms}$, flip angle $90^{\circ}$, FOV $240 \times 240 \mathrm{~mm}^{2}$, matrix size $144 \times$ 144, 85 slices, $1.7 \mathrm{~mm}$ slice thickness, 51 gradient directions with $b=900 \mathrm{~s} / \mathrm{mm}^{2}$ and eight additional $b=0$ images).

\section{Image Processing}

The data were manually inspected for any signal dropouts or artifacts and all subjects who did not pass our quality control procedure were not included in this study. The diffusion data were corrected for motion artifacts by means of affine registration with a reference b0 volume (FLIRT, FSL, Oxford). Diffusion gradients were compensated for rotations. Each anatomical T1 image was parcellated using the FreeSurfer software (http:// surfer.nmr.mgh.harvard.edu), resulting into 176 gray matter (GM), white matter (WM), and cerebrospinal fluid (CSF) sections. The resulting segmentation was mapped onto the diffusion space by registering the $\mathrm{T} 1$ image with the $\mathrm{T} 2$ image (rigid registration, FLIRT, FSL), and registering the T2 image with a b0 image (non-linear registration, FNIRT, FSL). A variational algorithm [Pasternak et al., 2009] was used to calculate the tissue FA $\left(\mathrm{FA}_{\mathrm{t}}\right)$ and free-water fraction $(\omega)$ at each voxel in the brain. The software for this algorithm was 
written in-house in Matlab (Mathworks). Subsequently, heterogeneity in tissue $\mathrm{FA}_{t}\left(\mathrm{HFA}_{t}\right)$ was computed for each desired ROI (e.g., cortical lobes-frontal, parietal, temporal, and occipital). We should however note that any errors due to suboptimal correction of motion or eddy current artifacts would also be reflected in the computation of average $\mathrm{FA}_{t}$ and heterogeneity $\left(\mathrm{HFA}_{\mathrm{t}}\right.$ ) (similar to all studies done using diffusion MRI). Given that these values are averaged over a large ROI, we expect the effect of these errors to be significantly reduced.

\section{RESULTS}

For all the subjects, we estimated a single diffusion tensor and an isotropic "free-water" term at every voxel in the brain [Pasternak et al., 2009]. The free-water compartment provides the volume fraction of the signal corresponding to the extracellular space, whereas the diffusion tensor characterizes diffusion associated to brain tissue. From the diffusion tensor, we computed the tissue fractional anisotropy $\left(\mathrm{FA}_{\mathrm{t}}\right)$ at each voxel, corresponding to the anisotropy due to the tissue component. Freesurfer [Fischl, 2012] software was used to parcellate the brain into various anatomical regions and heterogeneity in $\mathrm{FA}_{t}\left(\mathrm{HFA}_{\mathrm{t}}\right)$ was computed for a desired ROI. This measure of heterogeneity captures the variability in $\mathrm{FA}_{t}$ within a region-of-interest. We should note that the tissue fractional anisotropy $\mathrm{FA}_{t}$ is different than the traditionally used FA values computed from single tensor estimation. We expect that the traditionally computed FA values will in general be lower than $\mathrm{FA}_{\mathrm{t}}$ since the isotropic component is not "removed" from the single tensor based FA values. Thus, the values for $\mathrm{FA}_{\mathrm{t}}$ reported in our work are higher than those reported for $\mathrm{FA}$ in other works [Pfefferbaum et al., 2010].

\section{Age-Related Posterior to Anterior Increase in Heterogeneity}

We computed average $\mathrm{FA}_{t}$ and heterogeneity in tissue $\mathrm{FA}_{\mathrm{t}}\left(\mathrm{HFA}_{\mathrm{t}}\right)$ in the cortical gray matter for each of the anatomical lobes (both hemispheres): frontal, parietal, occipital, and temporal. $\mathrm{HFA}_{t}$ was computed for each ROI by first computing $\mathrm{FA}_{t}$ at each voxel and then using Eq. (2) by setting $m=\mathrm{FA}_{\mathrm{t}}$ (see Methods section). For each of the lobes, we computed the correlation coefficient between age and $\mathrm{HFA}_{\mathrm{t}}$. This (along with the statistical significance) can be computed using the Matlab (www.mathworks.com) function "corrcoef." Figure 3 shows a color-coded map of the correlation coefficient displayed for each of the lobes for both hemispheres. As can be seen, the rate of increase in heterogeneity is fastest in the frontal lobe, followed by the parietal, occipital, and temporal lobes in that order. Specifically, the increase in heterogeneity $\left(\mathrm{HFA}_{\mathrm{t}}\right)$ is statistically significant $(P<0.001)$ only in the frontal and parietal lobes, with the most increase in the frontal lobe (see Fig. 4 and Table I). No change in $\mathrm{HFA}_{t}$ is seen for the temporal and occipital lobes. Furthermore, the average $\mathrm{FA}_{t}$ in all the gray matter lobes increases significantly with age (see Fig. 5 and Table I).

Increase in heterogeneity in $\mathrm{FA}_{\mathrm{t}}$ in the fronto-parietal lobes indicates an increase in variability of the tissue diffusion properties. This indicates that the neurobiological structure of the fronto-parietal gray matter is more similar throughout the region at young age, but becomes distinct, patchy and dissimilar with increasing age (see Fig. 2). Thus, the cell 
bodies within the gray matter have very different structural layout in neighboring voxels (spatial locations) in older adults compared to younger ones. This can potentially affect the way these neurons "fire" (excite) in the gray matter of older adults.

Furthermore, there is virtually no change in heterogeneity in the temporal and occipital lobes, even though the $\mathrm{FA}_{\mathrm{t}}$ in these regions increases significantly (see Fig. 5). A similar phenomenon is seen in task-based functional neuroimaging studies, that is, there is an agerelated reduction in occipital activity coupled with an increase in frontal activity [Davis et al., 2008; Grady et al., 1994] indicating a posterior to anterior shift in aging (PASA model). Thus, examining the structural changes in terms of the heterogeneity in $\mathrm{FA}_{t}\left(\mathrm{HFA}_{t}\right)$ provides a complementary view to the observed functional alterations seen in aging.

We performed a similar analysis using the tissue mean diffusivity $\left(\mathrm{MD}_{\mathrm{t}}\right)$ by computing the average $\mathrm{MD}_{\mathrm{t}}$ and heterogeneity in $\mathrm{MD}_{\mathrm{t}}\left(\mathrm{HMD}_{\mathrm{t}}\right)$ in the four anatomical lobes of all subjects. $\mathrm{HMD}_{\mathrm{t}}$ showed an analogous trend as that of $\mathrm{HFA}_{t}$ with the frontal lobe showing the highest correlation with age, followed by the parietal, temporal, and occipital lobes (see Fig. 6 and Table II). These results support the "retrogenesis" hypothesis of aging, which states that the regions that are last to develop (e.g., frontal lobe) are the first to deteriorate [Reisberg et al., 1999].

\section{Examining Heterogeneity in the Cortical Hemispheres}

Figure 7 shows the correlation between age and heterogeneity in $\mathrm{FA}_{t}\left(\mathrm{HFA}_{t}\right)$ in the cortical gray matter of both the hemispheres (right hemisphere-correlation coefficient [cc] $=0.58$, $P=10^{-9}$ ), and left hemisphere (cc $=0.49, P=10^{-6}$ ). In general, $\mathrm{HFA}_{\mathrm{t}}$ is higher in the right hemisphere than the left hemisphere. Also, a two-tailed $t$-test shows that the heterogeneity $\mathrm{HFA}_{\mathrm{t}}$ in the right hemisphere is statistically different than in the left with a $P$-value of $1.2 \times$ $10^{-8}$. This can also be seen in Figure 3 (see the contrasts in the colors of the corresponding lobes in each hemisphere). Another fact that can be deduced from the results on heterogeneity examined above (Fig. 3, Fig. 5, and Fig. 7) is that the right and left hemispheres of the brain become increasingly dissimilar to each other during aging. Figure 7 shows that the slopes of the lines for both hemispheres diverge with increasing age indicating increasing dissimilarity with age. This is also confirmed from Figure 8, which was computed by subtracting the heterogeneity of the left hemisphere (cortex) from the right, indicating that the hemispheric differences in heterogeneity $\left(\mathrm{HFA}_{\mathrm{t}}\right)$ increase with age. Note that, this age-related hemispheric dissimilarity is statistically significant with $P=$ 0.005 . Thus, the gray matter in the right hemisphere becomes more distinct and dissimilar in its structure with age, indicating that it "ages faster" than the left hemisphere, thus reinforcing the "right-hemi" aging model.

Further, note that in only about 6 cases out of a total of 85 , the hemispheric differences in $\mathrm{HFA}_{t}$ is negative, that is, in only about 6 cases (out of 85) $\mathrm{HFA}_{t}$ in the right is less than in the left hemisphere (see Fig. 8 above). From the data presented above, we can draw the following conclusions:

1. $H_{F A}$ in the right hemisphere is statistically different than in the left hemisphere $\left(P=1.2 \times 10^{-8}\right)$. 
2. A $t$-test with the null-hypothesis that the hemispheric differences in $\mathrm{HFA}_{\mathrm{t}}$ are different from zero gave a $P$-value of $10^{-24}$. This implies that $\mathrm{HFA}_{\mathrm{t}}$ in the right hemisphere is higher than in the left hemisphere (at a group statistical level). Note that the difference in $\mathrm{HFA}_{\mathrm{t}}$ between the right and left hemisphere is positive for most cases (see Fig. 8).

3. Hemispheric differences in $\mathrm{HFA}_{\mathrm{t}}$ between the right and left hemispheres increase statistically significantly with age (from Fig. $8, P=0.005$ ).

\section{Examining Heterogeneity in the Functional Zones}

We grouped the Desikan parcellation [Desikan et al., 2006] of gray matter cortices obtained from Freesurfer [Fischl, 2012] into three functional zones: primary, paralimbic, and associative. The primary motor, somatosensory, and visual cortices formed the primary areas; cingulate, entorhinal, parahippocampal, temporal pole, and medial orbitofrontal cortices formed the paralimbic areas; and the remaining cortices were grouped into the associative areas. As seen in Figure 9, heterogeneity $\left(\mathrm{HFA}_{t}\right)$ increased significantly in the primary and the association areas but remained virtually unchanged in the paralimbic areas. Further, average $\mathrm{FA}_{\mathrm{t}}$ increased in all the three zones as detailed in Table III. Thus, the increase in $\mathrm{FA}_{\mathrm{t}}$ is "global" in the paralimbic areas, but local and distributed in the primary and association cortices resulting in an increase in heterogeneity in these regions. We should note that a global uniform change in $\mathrm{FA}_{t}$ does not change the heterogeneity $\left(\mathrm{HFA}_{t}\right)$ of an ROI, but local and isolated changes can cause an increase in $\mathrm{HFA}_{t}$. Thus, the paralimbic areas seem to be quite resilient during early aging, which offers structural evidence to support studies indicating better emotional regulation in older adults [Leclerc and Kensinger, 2008].

Increase in heterogeneity in the primary areas indicates the need to use more resources during manual tasks, which has been seen in functional studies [Fling et al., 2012; Riecker et al., 2006]. Further, there is evidence from neurochemical analysis of the motor cortices indicating changes in the dopaminergic system during healthy aging [Kaasinen and Rinne, 2002]. Our work confirms that structural changes do occur in the primary cortices during early aging. In fact, the proposed measure of heterogeneity is an early indicator of structural changes occurring in the brain.

\section{Examining Heterogeneity in the Sub-cortical Regions}

Heterogeneity was computed in the following sub-cortical regions of both the hemispheres: thalamus, globus pallidus, ventral DC, caudate, putamen, amygdala, nucleus accumbens, and hippocampus. Regions were grouped based on whether $\mathrm{HFA}_{t}$ correlated positively, negatively, or remained unchanged with age (see Fig. 10). It was observed that the regions involved in memory systems, that is, hippocampus and caudate showed an increase in heterogeneity $\left(\mathrm{HFA}_{t}\right)$ along with a significant increase in the average FA $\mathrm{t}_{\mathrm{t}}$ (Fig. 10, Table IV). Thus, these regions showed a neural degeneration with age implying a possible decrease in performance on memory related tasks, as has been recorded in other published works [Singh-Manoux et al., 2012; West et al., 1992]. Regions such as the thalamus, nucleus accumbens, and amygdala, which are involved in emotional regulation and reward 
mechanism, did not show any change in heterogeneity or average values of $\mathrm{FA}_{\mathrm{t}}$ across the age-range analyzed in this work. This observation concurs with other cognitive studies, which have also reported little effect of age on emotional regulation [Nashiro et al., 2012]. Conversely, sub-cortical structures such as, putamen, globus pallidus, and ventral DC, which are involved in involuntary motor function, show a statistically significant decrease in heterogeneity. This is in sharp contrast to the average $\mathrm{FA}_{\mathrm{t}}$ in these areas, which shows no correlation with age (Table IV, Fig. 11). Thus, age seems to be having a homogenizing effect in these regions, with the diffusion MRI deduced tissue properties becoming increasingly similar.

In addition, as the hippocampus is composed of several diverse structures, in Figure 12, we show the estimated heterogeneity $\left(\mathrm{HFA}_{\mathrm{t}}\right)$ separately for this region. As expected, heterogeneity increased significantly $(P<0.001)$ with age in both hemispheres indicating an age-induced increased dissimilarity in structural organization of this region.

\section{Accounting for Partial-Volume Effects}

The dMRI data used in this study had a spatial resolution of $1.7 \times 1.7 \times 1.7 \mathrm{~mm}^{3}$, which is the highest one can achieve on a 3T clinical scanner without significantly affecting the signal-to-noise ratio (SNR). Yet the data are affected by partial-volume effects especially at the boundary between gray-white and gray-CSF areas. Although the free-water model used in this study can significantly reduce the effects of CSF contamination [Metzler-Baddeley et al., 2012], the effect of gray-white partial-voluming at the boundary between the gray and white matter regions is difficult to remove [Alexander et al., 2001]. To ensure that partial volume effects do not primarily drive the results reported in this work, we removed every voxel from the gray matter ROI (say, the frontal lobe) if at-least one of its neighbors (in a 3 $\times 3 \times 3$ voxel neighborhood) was classified as white matter by the Freesurfer software. Thus, all gray matter voxels that shared a boundary with white matter were removed and heterogeneity $\left(\mathrm{HFA}_{t}\right)$ was recomputed using the remaining voxels. Figure 13 shows the heterogeneity $\left(\mathrm{HFA}_{t}\right)$ computed for the four lobes: frontal, parietal, temporal, and occipital. As seen in this figure and Table $\mathrm{V}$, a similar pattern as seen in Figure 4 emerges with $\mathrm{HFA}_{t}$ increase being the highest in frontal lobe, followed by parietal, occipital, and temporal lobe. This indicates that partial-volume effects do not drive our results and that the tissue gray matter structure indeed degenerates with age as quantified by our measure of heterogeneity.

\section{DISCUSSION}

In this work, we analyzed gray matter alterations in the brain in early aging using diffusion MRI. To the best of our knowledge, this is the first report that analyzes the alterations in gray matter structure of anatomical lobes, functional zones and sub-cortical areas using diffusion MRI. We proposed a novel measure called "heterogeneity" which can measure the variability of any diffusion measure in a given region of interest. This is in contrast to traditional studies where only the "average" value of FA or mean diffusivity (MD) is used. Note that, the average value does not necessarily capture the entire statistical knowledge that is known about FA (or MD) in a given ROI. Thus, examining heterogeneity can provide additional insight into the underlying changes within an ROI. 
Further, we used an advanced model of diffusion, which includes computing an isotropic "free-water" compartment corresponding to the extracellular space. This model can better explain the observed signal as has been reported by several works [Panagiotaki et al., 2012; Pasternak et al., 2009]. The tissue heterogeneity in $\mathrm{FA}_{t}\left(\mathrm{HFA}_{t}\right)$ computed using this model in several gray matter areas showed region specific changes with age. In particular, the proposed analysis provided the much-needed structural evidence to support functional patterns of aging seen in fMRI studies. We believe that this is a first such study that has attempted to connect the observations from fMRI studies (PASA, HAROLD, right-hemi models of aging) to a measure computed from diffusion MRI.

In this work, we studied lobar parcellations of the brain since work done in other domains (cognitive, structural as well as functional) used these regions in their analysis in the context of healthy aging. Thus, connecting the findings from other domains becomes natural and straightforward ("right-hemi" aging model, PASA, retrogenesis, etc.). Analyzing the four anatomical lobes (frontal, parietal, temporal, and occipital) in terms of heterogeneity in $\mathrm{FA}_{\mathrm{t}}$ $\left(\mathrm{HFA}_{\mathrm{t}}\right)$ revealed a pattern that is strikingly similar to that observed during task-based fMRI and PET studies. These studies have reported an age-related reduction in occipital activity coupled with an increase in frontal activity [Davis et al., 2008; Grady et al., 1994]. This pattern is known as the posterior-anterior shift in aging or the PASA model. This model has been found across a variety of cognitive functions, including visual perception and attention [Huettel et al., 2001; Iidaka et al., 2002; Madden et al., 2002], visuospatial memory [Nyberg et al., 2003], working memory [Grossman et al., 2002; Rypma and D'Esposito, 2000], and episodic memory encoding and retrieval [Cabeza et al., 2004; Gutchess et al., 2005]. Thus, the PASA pattern has been widely observed in functional neuroimaging studies on aging. However, to the best of our knowledge, this is the first study that has provided a complementary view of the PASA model using measures derived from diffusion MRI. In particular, Figures 3 and Figure 4 show a significant increase in heterogeneity with age in the frontal and parietal lobes, but not in the occipital and temporal lobes. Increase in heterogeneity implies increased dissimilarity in the structure of gray matter in these regions. We speculate that an increase in heterogeneity could imply less efficient neural processing of information or increased degeneration of the gray matter tissue as has been reported in several studies [Kalpouzos et al., 2009; Montembeault et al., 2012].

Another model observed from fMRI studies is the HAROLD (hemispheric asymmetry reduction in older adults) model of aging. This model states that, under similar circumstances, prefrontal activity during cognitive performances tends to be less lateralized in older adults than in younger ones. This model is further supported by evidence from the domains of episodic memory, semantic memory, working memory, perception, and inhibitory control [Cabeza, 2002]. We believe that due to the increasing hemispheric differences in heterogeneity with age (Fig. $8, P=0.005$ ), a given task might require more resources from both hemispheres in older adults as compared to younger ones. Specifically, in this work, all our subjects are right-handed males. Thus, several tasks that require bilateral activation (language, speech, visual and auditory processing, etc.) are highly lateralized, with the left hemisphere being the dominant hemisphere. Thus, during these tasks, the left 
hemisphere is more "activated" than the right (which leads to laterality observed in fMRI studies).

We speculate that increase in heterogeneity implies increase in tissue dissimilarity, which could lead to an increase in "activation" during functional tasks to maintain the same level of functional performance. As $\mathrm{HFA}_{\mathrm{t}}$ is higher in the right hemisphere (compared to left) at older age, it could imply more resources required from that hemisphere, thus reducing the laterality. In other words, since the right hemisphere is aging faster than the left one (Fig. 8), much more resources are used by the right hemisphere to perform the same task compared to younger adults, thus causing a reduction in laterality (laterality will be maintained if both the hemispheres "aged" in a similar fashion or had equal increase in heterogeneity). This idea (of reduced laterality) due to increased activity in the right hemisphere to maintain the same level of syntactic function has also been shown in functional MRI studies by [Tyler et al., 2010]. Our results on heterogeneity are also in-line with these functional observations defined by the HAROLD model of aging [Cabeza, 2002; Dolcos et al., 2002]. We should note that, this "speculation" is valid only for right-handed subjects and in tasks that are bilateral but predominantly processed in the left hemisphere.

Analyzing heterogeneity in the functional zones (primary, paralimbic, and association) provides a different view of the process of aging. Primary area, which is composed of the motor and visual cortices, shows a marked increase in heterogeneity indicating deterioration in these regions (and the corresponding functions). This is also supported by studies from other domains that have reported an age-related decline in fine motor function [Rypma and D'Esposito, 2000]. Structural MRI (sMRI) studies [Salat et al., 2004] have also shown a decrease in cortical thickness in the primary motor and somatosensory cortices with age. Further, fMRI studies have shown over-recruitment of bilateral motor cortices by older adults while performing unimanual movements indicating inefficient use of brain resources [Fling et al., 2012; Riecker et al., 2006]. In addition, there are significant differences in the brain neurochemistry between young and older adults, many of which have been directly linked to deficits in motor performance for older adults [Bartus et al., 1982; Kaasinen and Rinne, 2002; Seidler et al., 2010]. Thus, there is increasing evidence that the cortices associated with motor function deteriorate with age. We should however note that, the proposed work shows increased heterogeneity in the primary cortices in early aging (ages less than 55 years) indicating that the diffusion MRI-based measure of heterogeneity is an early and sensitive marker of gray matter alterations.

This study also shows that the paralimbic areas are quite resilient to the effects of aging in terms of heterogeneity. Volumetric studies based on structural MRI have also shown similar results [Grieve et al., 2005; Terribilli et al., 2011]. Further, cognitive studies have found little effect of age on emotional regulation, which is primarily processed by the limbic and paralimbic structures [Leclerc and Kensinger, 2008; Nashiro et al., 2012]. Thus, the proposed work supports these observations from the perspective of diffusion MRI.

$\mathrm{HFA}_{\mathrm{t}}$ was also analyzed in the various sub-cortical regions by grouping them based on whether heterogeneity was positively or negatively correlated with age. This grouping revealed that aging affects the sub-cortical regions differently based on their function 
(emotional processing, motor control, or memory). Thus, increased heterogeneity was found in areas associated with memory (caudate and hippocampus) indicating a negative effect on the functioning of these systems. Specifically, the hippocampus showed a very high increase in heterogeneity with age (Fig. 12), which coincides with a decrease in memory performance with age, consistent with results reported in cognitive studies [Singh-Manoux et al., 2012; West et al., 1992]. Aging hardly affects areas involved in emotional regulation [Nashiro et al., 2012], an effect also seen in this study where little to no change in heterogeneity is observed in areas such as thalamus, amygdala and nucleus accumbens. Conversely, subcortical structures such as, putamen, globus pallidus, and ventral DC, which are involved in involuntary motor function, show a statistically significant decrease in heterogeneity (but no change in average $\mathrm{FA}_{\mathrm{t}}$ ). This implies that the structural layout of cells in these regions becomes increasingly similar with age and could potentially lead to a more efficient processing during a given task.

Another phenomenon that finds support from this work is the "right-hemi" aging model. As seen in Figure 8, the right hemisphere has consistently higher heterogeneity than the left throughout the age span analyzed here. We should however note that, all our subjects were primarily right-handed males. Thus, little can be said about the effect of handedness or gender on the "right-hemi" aging model.

Studies on cortical gray matter maturation [Gogtay et al., 2004; Lebel et al., 2008] have shown that the first cortices to develop are in the temporal and occipital lobes, followed by the parietal and frontal regions. In contrast, the "first-in last-out" (retrogenesis) hypothesis of brain atrophy states that the regions that are last to develop are the first to atrophy [Bartzokis et al., 2004; Salat et al., 2004]. From Figures 3 and Figure 4, we also see that $\mathrm{HFA}_{\mathrm{t}}$ (heterogeneity) increases mainly in the fronto-parietal regions, but not in the temporal and occipital lobes during early aging. Thus, our work on heterogeneity also shows similar trends, that is, increased degeneration (heterogeneity) is seen in areas that are last to develop (frontal lobes). Moreover, our observations that the heterogeneity increases were statistically significant in the primary and association zones, but not in the paralimbic areas further emphasize this concept. We thus believe, that this work further strengthens the "first-in lastout" (retrogenesis) hypothesis of aging.

In general, an increase in average $\mathrm{FA}_{\mathrm{t}}$ with age is seen throughout the cortical gray matter regions (Fig. 5). We should specifically note that, the average values of $\mathrm{FA}_{\mathrm{t}}$ are higher than those reported for FA using the single tensor model. This is because our model removes the isotropic free-water compartment, leading to a more anisotropic estimation of the single tensor. Increase in $\mathrm{FA}_{\mathrm{t}}$ indicates a more anisotropic layout in the gray matter. This could be due to dendrite pruning that occurs with increasing age, as has been shown in animal and human post-mortem studies [Hof and Morrison, 2004; Jacobs et al., 1997]. Dendrite pruning could potentially lead to a more directionally specific diffusion of water as opposed to a more isotropic diffusion observed in young age due to the presence of dendrites in all directions. In addition, an increase in gray matter FA has been shown in cases of mild traumatic brain injury (mTBI), which was correlated with an increase in glial fibrillary acidic protein (GFAP) in gray matter [Budde et al., 2011; Bouix et al., 2013]. We should 
note that this could be one of the many reasons for an increase in $\mathrm{FA}_{t}$. Thus, while dMRI is sensitive to small changes, it cannot pinpoint the exact cause of those changes.

We have also observed a statistically significant increase in the amount of extracellular freewater component throughout the brain with increasing age $(P<0.001)$. Further (see Supporting Information), we also see an increase in average mean diffusivity $\left(\mathrm{MD}_{\mathrm{t}}\right)$ in all anatomical lobes, while the heterogeneity in $\mathrm{MD}_{t}\left(\mathrm{HMD}_{t}\right)$ follows similar trends to $\mathrm{HFA}_{t}$ in all regions of the brain. This could be due to a combined effect of brain atrophy and increased inflammation during aging, as has been reported by several studies on neurochemical analysis of the brain [von Bernhardi et al., 2010]. Inflammation is mainly driven by increased microglial cell reactivity [Lovell et al., 2001] along with an increasing level of circulating cytokines [Streit et al., 2004]. Uneven distribution of these neurochemicals and the microglia cells could be one of the contributing factors in increased heterogeneity seen in the cortical gray matter regions of older adults. Further, changes in the laminar structure of the gray matter as well as the organization of the dendrites could also affect heterogeneity in addition to other changes in tissue structure.

We should also note a limitation of this study. Because of the limited sample size, our work may be characterizing the increase in heterogeneity in terms of a linear model (straight line fit), whereas the actual variation could be nonlinear (quadratic or cubic), as has been reported for FA changes in white matter [Kochunov et al., 2011]. Thus, this analysis needs to be repeated on data with larger sample size, to better characterize the change in heterogeneity across the lifespan.

As mentioned earlier, several models of aging (HAROLD, PASA, right-hemi aging, retrogenesis) have been proposed based on observational studies done using functional and structural neuroimaging. Although the cognitive aspects of these models have been analyzed, very little is known about the structural gray matter alterations that provide a complementary view of these models. Thus, one of the main themes of this article was to examine gray matter changes in early aging using a measure derived from diffusion MRI data. This is extremely important, as it connects the structural and functional domains and provides a better understanding of the aging process.

\section{Acknowledgments}

Contract grant sponsor: National Institute of Health (NIH); Contract grant numbers: R01MH097979 (Rathi), R01 NS 078337 (Shenton), R01 MH082918 (Shenton), R01MH074794 (Westin), P41RR013218, P41EB015902 (PI: Dr. Kikinis, Core PI: Dr. Westin), R01 AG042512 (Kubicki, Makris), and R21NS079905, R21NS077059 (Dickerson).

\section{REFERENCES}

Alexander AL, Hasan KM, Lazar M, Tsuruda JS, Parker DL. Analysis of partial volume effects in diffusion-tensor MRI. Magn Reson Med. 2001; 45:770-780. [PubMed: 11323803]

Allen JS, Bruss J, Brown CK, Damasio H. Normal neuroanatomical variation due to age: The major lobes and a parcellation of the temporal region. Neurobiol Aging. 2005; 26:1245-1260. [PubMed: 16046030]

Bartus RT, Dean RLIII, Beer B, Lippa AS. The cholinergic hypothesis of geriatric memory dysfunction. Science. 1982; 217:408-414. [PubMed: 7046051] 
Bartzokis G, Sultzer D, Lu PH, Nuechterlein KH, Mintz J, Cummings JL. Heterogeneous age-related breakdown of white matter structural integrity: Implications for cortical "disconnection" in aging and Alzheimer's disease. Neurobiol Aging. 2004; 25:843-851. [PubMed: 15212838]

Basser PJ, Pierpaoli C. Microstructural and physiological features of tissues elucidated by quantitativediffusion-tensor MRI. J Magn Reson Series B. 1996; 111:209-219.

Bhagat YA, Beaulieu C. Diffusion anisotropy in subcortical white matter and cortical gray matter: changes with aging and the role of CSF-suppression. J Magn Reson Imaging. 2004; 20:216-227. [PubMed: 15269946]

Bouix S, Pasternak O, Rathi Y, Pelavin PE, Zafonte R, Shenton ME. Increased gray matter diffusion anisotropy in patients with persistent post-concussive symptoms following mild traumatic brain injury. PLoS One. 2013; 8:e66205. [PubMed: 23776631]

Bronson RT, Lipman RD, Harrison DE. Age-related gliosis in the white matter of mice. Brain Res. 1993; 609:124-128. [PubMed: 8508295]

Budde MD, Janes L, Gold E, Turtzo LC, Frank JA. The contribution of gliosis to diffusion tensor anisotropy and tractography following traumatic brain injury: Validation in the rat using Fourier analysis of stained tissue sections. Brain. 2011; 134:2248-2260. [PubMed: 21764818]

Cabeza R. Hemispheric asymmetry reduction in older adults: The HAROLD model. Psychol Aging. 2002; 17:85-100. [PubMed: 11931290]

Cabeza R, Anderson ND, Locantore JK, McIntosh AR. Aging gracefully: Compensatory brain activity in high-performing older adults. NeuroImage. 2002; 17:1394-1402. [PubMed: 12414279]

Cabeza R, Daselaar SM, Dolcos F, Prince SE, Budde M, Nyberg L. Task-independent and taskspecific age effects on brain activity during working memory, visual attention and episodic retrieval. Cereb Cortex. 2004; 14:364-375. [PubMed: 15028641]

Calderini G, Bonetti A, Battistella A, Crews F, Toffano G. Biochemical changes of rat brain membranes with aging. Neurochem Res. 1983; 8:483-491. [PubMed: 6310426]

Davis SW, Dennis NA, Daselaar SM, Fleck MS, Cabeza R. Que PASA? The posterior-anterior shift in aging. Cereb Cortex. 2008; 18:1201-1209. [PubMed: 17925295]

Desikan RS, Segonne F, Fischl B, Quinn BT, Dickerson BC, Blacker D, Buckner RL, Dale AM, Maguire RP, Hyman BT, Albert MS, Killiany RJ. An automated labeling system for subdividing the human cerebral cortex on MRI scans into gyral based regions of interest. NeuroImage. 2006; 31:968-980. [PubMed: 16530430]

Dolcos F, Rice HJ, Cabeza R. Hemispheric asymmetry and aging: Right hemisphere decline or asymmetry reduction. Neurosci Biobehav Rev. 2002; 26:819-825. [PubMed: 12470693]

Fischl B. FreeSurfer. Neuro Image. 2012; 62:774-781. [PubMed: 22248573]

Fling BW, Kwak Y, Peltier SJ, Seidler RD. Differential relationships between transcallosal structural and functional connectivity in young and older adults. Neurobiol Aging. 2012; 33:2521-2526. [PubMed: 22177217]

Gogtay N, Giedd JN, Lusk L, Hayashi KM, Greenstein D, Vaituzis AC, Nugent TFIII, Herman DH, Clasen LS, Toga AW, Rapoport JL, Thompson PM. Dynamic mapping of human cortical development during childhood through early adulthood. Proc Natl Acad Sci USA. 2004; 101:8174-8179. [PubMed: 15148381]

Grady CL, Maisog JM, Horwitz B, Ungerleider LG, Mentis MJ, Salerno JA, Pietrini P, Wagner E, Haxby JV. Age-related changes in cortical blood flow activation during visual processing of faces and location. J Neurosci. 1994; 14:1450-1462. [PubMed: 8126548]

Grieve SM, Clark CR, Williams LM, Peduto AJ, Gordon E. Preservation of limbic and paralimbic structures in aging. Hum Brain Mapp. 2005; 25:391-401. [PubMed: 15852381]

Grossman M, Cooke A, DeVita C, Alsop D, Detre J, Chen W, Gee J. Age-related changes in working memory during sentence comprehension: An fMRI study. NeuroImage. 2002; 15:302-317. [PubMed: 11798267]

Gunning-Dixon FM, Brickman AM, Cheng JC, Alexopoulos GS. Aging of cerebral white matter: a review of MRI findings. Int J Geriatr Psychiatry. 2009; 24:109-117. [PubMed: 18637641]

Gutchess AH, Welsh RC, Hedden T, Bangert A, Minear M, Liu LL, Park DC. Aging and the neural correlates of successful picture encoding: Frontal activations compensate for decreased medialtemporal activity. J Cogn Neurosci. 2005; 17:84-96. [PubMed: 15701241] 
Helenius J, Soinne L, Perkio J, Salonen O, Kangasmaki A, Kaste M, Carano RA, Aronen HJ, Tatlisumak T. Diffusion-weighted MR imaging in normal human brains in various age groups. AJNR Am J Neuroradiol. 2002; 23:194-199. [PubMed: 11847041]

Hof PR, Morrison JH. The aging brain: Morphomolecular senescence of cortical circuits. Trends Neurosci. 2004; 27:607-613. [PubMed: 15374672]

Huettel SA, Singerman JD, McCarthy G. The effects of aging upon the hemodynamic response measured by functional MRI. NeuroImage. 2001; 13:161-175. [PubMed: 11133319]

Iidaka T, Okada T, Murata T, Omori M, Kosaka H, Sadato N, Yonekura Y. Age-related differences in the medial temporal lobe responses to emotional faces as revealed by fMRI. Hippocampus. 2002; 12:352-362. [PubMed: 12099486]

Jacobs B, Driscoll L, Schall M. Life-span dendritic and spine changes in areas 10 and 18 of human cortex: a quantitative Golgi study. J Comp Neurol. 1997; 386:661-680. [PubMed: 9378859]

Kaasinen V, Rinne JO. Functional imaging studies of dopamine system and cognition in normal aging and Parkinson's disease. Neurosci Biobehav Rev. 2002; 26:785-793. [PubMed: 12470690]

Kalpouzos G, Chételat G, Baron J-C, Landeau B, Mevel K, Godeau C, Barré L, Constans J-M, Viader F, Eustache F, Desgranges B. Voxel-based mapping of brain gray matter volume and glucose metabolism profiles in normal aging. Neurobiol Aging. 2009; 30:112-124. [PubMed: 17630048]

Kochunov P, Glahn DC, Lancaster J, Thompson PM, Kochunov V, Rogers B, Fox P, Blangero J, Williamson DE. Fractional anisotropy of cerebral white matter and thickness of cortical gray matter across the lifespan. NeuroImage. 2011; 58:41-49. [PubMed: 21640837]

Lebel C, Walker L, Leemans A, Phillips L, Beaulieu C. Microstructural maturation of the human brain from childhood to adulthood. NeuroImage. 2008; 40:1044-1055. [PubMed: 18295509]

Leclerc CM, Kensinger EA. Effects of age on detection of emotional information. Psychol Aging. 2008; 23:209-215. [PubMed: 18361668]

Lemaitre H, Goldman AL, Sambataro F, Verchinski BA, Meyer-Lindenberg A, Weinberger DR, Mattay VS. Normal age-related brain morphometric changes: nonuniformity across cortical thickness, surface area and gray matter volume? Neurobiol Aging. 2012; 33:617.e611-617.e619. [PubMed: 20739099]

Lovell MA, Xie C, Markesbery WR. Acrolein is increased in Alzheimer's disease brain and is toxic to primary hippocampal cultures. Neurobiol Aging. 2001; 22:187-194. [PubMed: 11182468]

Madden DJ, Bennett IJ, Song AW. Cerebral white matter integrity and cognitive aging: Contributions from diffusion tensor imaging. Neuropsychol Rev. 2009; 19:415-435. [PubMed: 19705281]

Madden DJ, Turkington TG, Provenzale JM, Denny LL, Langley LK, Hawk TC, Coleman RE. Aging and attentional guidance during visual search: Functional neuroanatomy by positron emission tomography. Psychol Aging. 2002; 17:24-43. [PubMed: 11931285]

Mandybur TI, Ormsby I, Zemlan FP. Cerebral aging: A quantitative study of gliosis in old nude mice. Acta Neuropathol. 1989; 77:507-513. [PubMed: 2718746]

Metzler-Baddeley C, O'Sullivan MJ, Bells S, Pasternak O, Jones DK. How and how not to correct for CSF-contamination in diffusion MRI. NeuroImage. 2012; 59:1394-1403. [PubMed: 21924365]

Montembeault M, Joubert S, Doyon J, Carrier J, Gagnon J-F, Monchi O, Lungu O, Belleville S, Brambati SM. The impact of aging on gray matter structural covariance networks. NeuroImage. 2012; 63:754-759. [PubMed: 22776455]

Nashiro K, Sakaki M, Mather M. Age differences in brain activity during emotion processing: reflections of age-related decline or increased emotion regulation? Gerontology. 2012; 58:156163. [PubMed: 21691052]

Nyberg L, Sandblom J, Jones S, Neely AS, Petersson KM, Ingvar M, Backman L. Neural correlates of training-related memory improvement in adulthood and aging. Proc Natl Acad Sci. 2003; 100:13728-13733. [PubMed: 14597711]

Panagiotaki E, Schneider T, Siow B, Hall MG, Lythgoe MF, Alexander DC. Compartment models of the diffusion MR signal in brain white matter: A taxonomy and comparison. NeuroImage. 2012; 59:2241-2254. [PubMed: 22001791]

Pasternak O, Shenton ME, Westin CF. Estimation of extracellular volume from regularized multi-shell diffusion MRI. Med Image Comput Comput Assist Interv. 2012a; 15:305-312. [PubMed: 23286062] 
Pasternak O, Sochen N, Gur Y, Intrator N, Assaf Y. Free water elimination and mapping from diffusion MRI. Magn Reson Med. 2009; 62:717-730. [PubMed: 19623619]

Pasternak O, Westin CF, Bouix S, Seidman LJ, Goldstein JM, Woo TU, Petryshen TL, MesholamGately RI, McCarley RW, Kikinis R, Shenton ME, Kubicki M. Excessive extracellular volume reveals a neurodegenerative pattern in schizophrenia onset. J Neurosci. 2012b; 32:17365-17372. [PubMed: 23197727]

Pfefferbaum A, Adalsteinsson E, Rohlfing T, Sullivan EV. Diffusion tensor imaging of deep gray matter brain structures: Effects of age and iron concentration. Neurobiol Aging. 2010; 31:482493. [PubMed: 18513834]

Reisberg B, Franssen EH, Hasan SM, Monteiro I, Boksay I, Souren LE, Kenowsky S, Auer SR, Elahi S, Kluger A. Retrogene-sis: Clinical, physiologic, and pathologic mechanisms in brain aging, Alzheimer's and other dementing processes. Eur Archiv Psychiatry Clin Neurosci. 1999; 3(249 Suppl):28-36.

Riecker A, Groschel K, Ackermann H, Steinbrink C, Witte O, Kastrup A. Functional significance of age-related differences in motor activation patterns. NeuroImage. 2006; 32:1345-1354. [PubMed: 16798017]

Rypma B, D'Esposito M. Isolating the neural mechanisms of age-related changes in human working memory. Nat Neurosci. 2000; 3:509-515. [PubMed: 10769393]

Sakai H, Takahara M, Honjo NF, Doi S, Sadato N, Uchiyama Y. Regional frontal gray matter volume associated with executive function capacity as a risk factor for vehicle crashes in normal aging adults. PLoS One. 2012; 7:e45920. [PubMed: 23029316]

Salat DH, Buckner RL, Snyder AZ, Greve DN, Desikan RS, Busa E, Morris JC, Dale AM, Fischl B. Thinning of the cerebral cortex in aging. Cereb Cortex. 2004; 14:721-730. [PubMed: 15054051]

Salat DH, Tuch DS, Hevelone ND, Fischl B, Corkin S, Rosas HD, Dale AM. Age-related changes in prefrontal white matter measured by diffusion tensor imaging. Ann N Y Acad Sci. 2005; 1064:3749. [PubMed: 16394146]

Schulze ET, Geary EK, Susmaras TM, Paliga JT, Maki PM, Little DM. Anatomical correlates of agerelated working memory declines. J Aging Res. 2011; 2011:606871. [PubMed: 22175019]

Seidler RD, Bernard JA, Burutolu TB, Fling BW, Gordon MT, Gwin JT, Kwak Y, Lipps DB. Motor control and aging: Links to age-related brain structural, functional, and biochemical effects. Neurosci Biobehav Rev. 2010; 34:721-733. [PubMed: 19850077]

Singh-Manoux A, Kivimaki M, Glymour MM, Elbaz A, Berr C, Ebmeier KP, Ferrie JE, Dugravot A. Timing of onset of cognitive decline: Results from Whitehall II prospective cohort study. BMJ. 2012; 344:d7622. [PubMed: 22223828]

Sloane J, Hollander W, Moss M, Rosene D, Abraham C. Increased microglial activation and protein nitration in white matter of the aging monkeys. Neurobiol Aging. 1999; 20:395-405. [PubMed: 10604432]

Sowell ER, Peterson BS, Thompson PM, Welcome SE, Henkenius AL, Toga AW. Mapping cortical change across the human life span. Nat Neurosci. 2003; 6:309-315. [PubMed: 12548289]

Squarzoni P, Tamashiro-Duran J, Souza Duran FL, Santos LC, Vallada HP, Menezes PR, Scazufca M, Filho GB, Alves TC. Relationship between regional brain volumes and cognitive performance in the healthy aging: an MRI study using voxel-based morphometry. J Alzheimers Dis. 2012; 31:4558. [PubMed: 22504316]

Steffener J, Brickman AM, Habeck CG, Salthouse TA, Stern Y. Cerebral blood flow and gray matter volume covariance patterns of cognition in aging. Hum Brain Mapp. 2012; 34:3267-3279. [PubMed: 22806997]

Streit WJ, Mrak RE, Griffin WS. Microglia and neuroinflammation: A pathological perspective. J Neuroinflammation. 2004; 1:14. [PubMed: 15285801]

Terribilli DB, Schaufelberger MS, Duran FLS, Zanetti MV, Curiati PK, Menezes PR, Scazufca M, Amaro E Jr, Leite CC, Busatto GF. Age-related gray matter volume changes in the brain during non-elderly adulthood. Neurbiol Aging. 2011; 32:354-368.

Tyler LK, Shafto MA, Randall B, Wright P, Marslen-Wilson WD, Stamatakis EA. Preserving syntactic processing across the adult life span: The modulation of the frontotemporal language 
system in the context of age-related atrophy. Cereb Cortex. 2010; 20:352-364. [PubMed: 19505991]

von Bernhardi R, Tichauer JE, Eugenín J. Aging-dependent changes of microglial cells and their relevance for neurodegenerative disorders. J Neurochem. 2010; 112:1099-1114. [PubMed: 20002526]

Wang Y, Wang Q, Haldar JP, Yeh FC, Xie M, Sun P, Tu TW, Trinkaus K, Klein RS, Cross AH, Song SK. Quantification of increased cellularity during inflammatory demyelination. Brain. 2011; 134:3590-3601. [PubMed: 22171354]

West RL, Crook TH, Barron KL. Everyday memory performance across the life span: Effects of age and noncognitive individual differences. Psychol Aging. 1992; 7:72-82. [PubMed: 1558708]

Zhang H, Schneider T, Wheeler-Kingshott CA, Alexander DC. NODDI: Practical in vivo neurite orientation dispersion and density imaging of the human brain. NeuroImage. 2012; 61:1000-1016. [PubMed: 22484410]

Zhu T, Hu R, Qiu X, Taylor M, Tso Y, Yiannoutsos C, Navia B, Mori S, Ekholm S, Schifitto G, Zhong J. Quantification of accuracy and precision of multi-center DTI measurements: A diffusion phantom and human brain study. NeuroImage. 2011; 56:1398-1411. [PubMed: 21316471] 


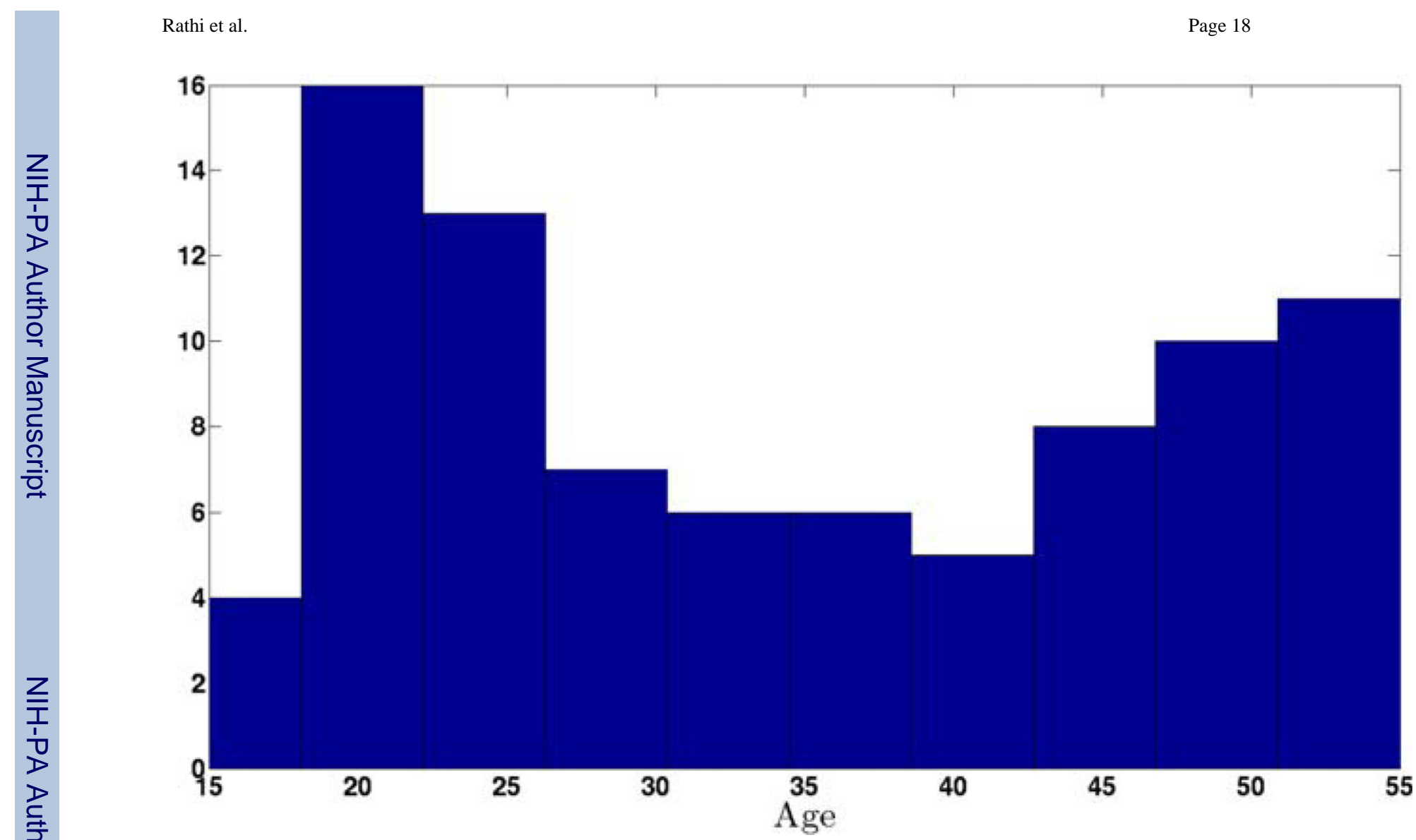

Figure 1.

Histogram of subjects ( $x$-axis is age) participating in this study. [Color figure can be viewed in the online issue, which is available at wileyonlinelibrary.com.] 

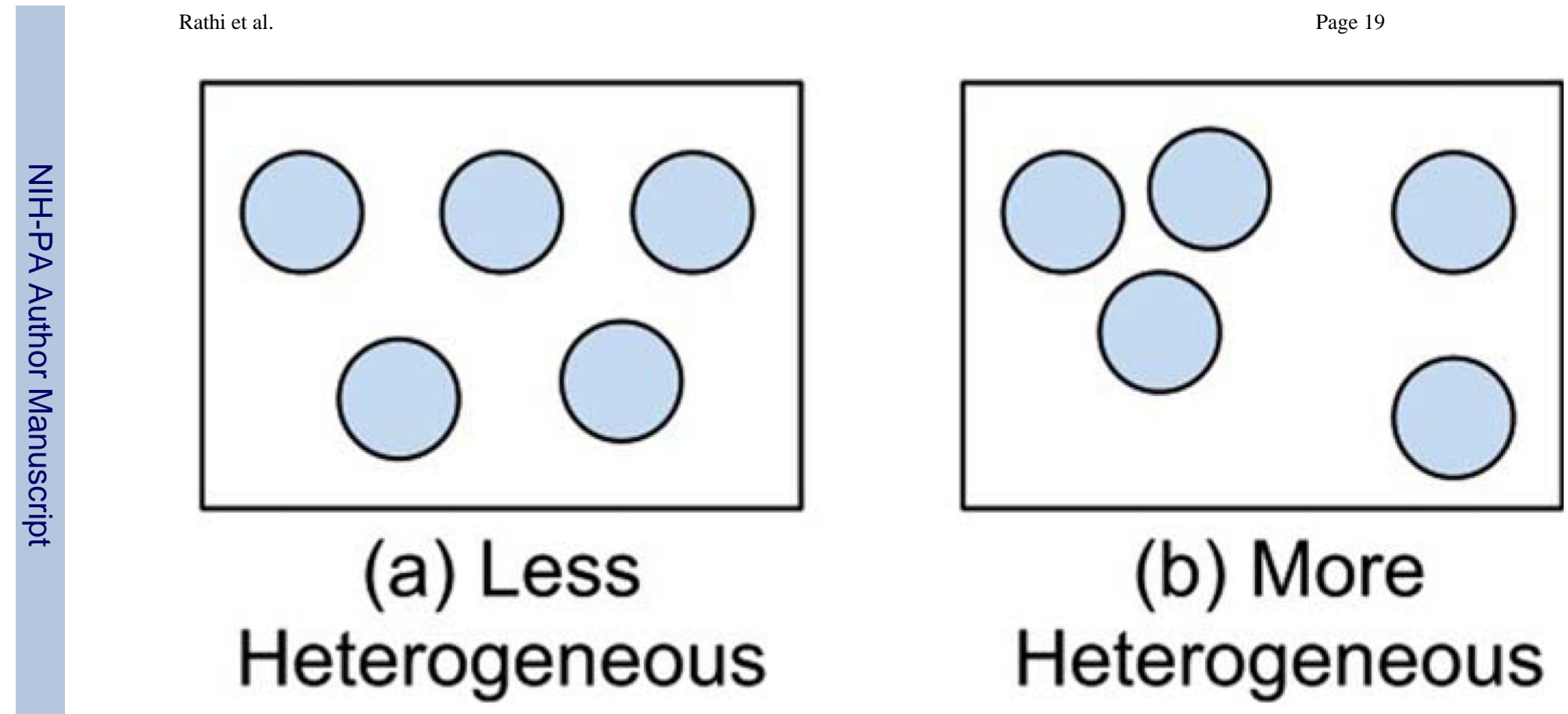

Figure 2.

A schematic depicting "less heterogeneous" and "more heterogeneous" spatial layout of cells. [Color figure can be viewed in the online issue, which is available at wileyonlinelibrary.com.] 


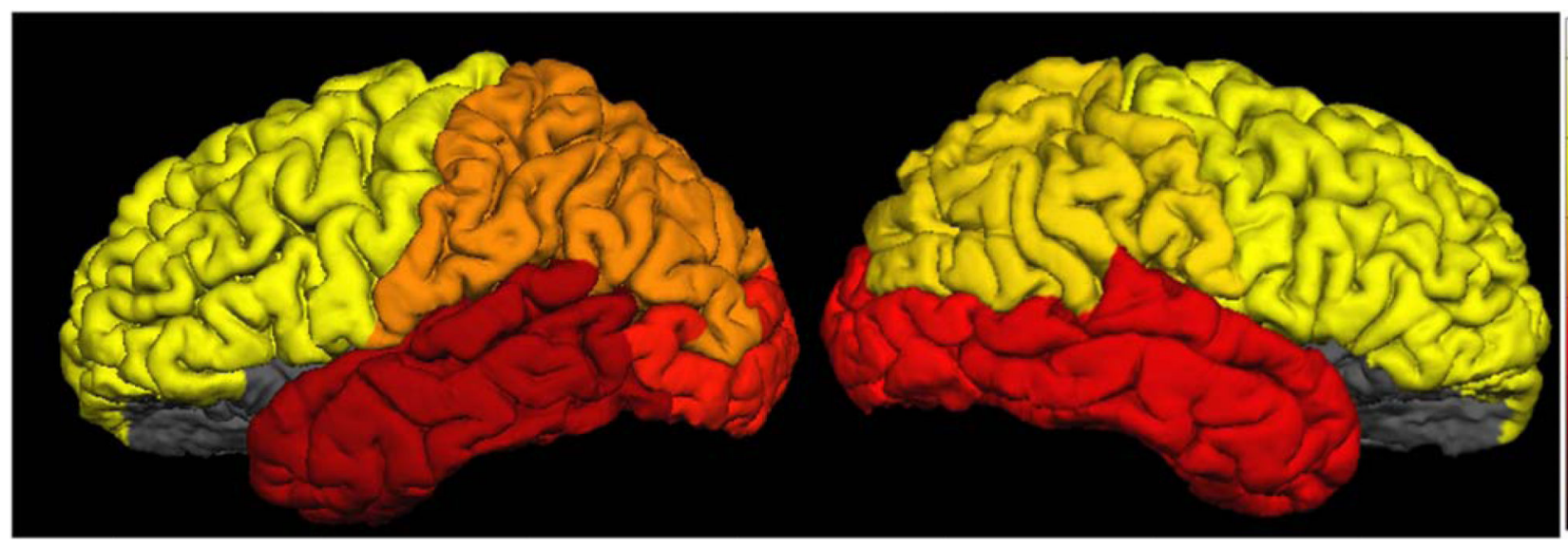

Figure 3.

Color-coded map of the correlation between age and heterogeneity in $\mathrm{FA}_{t}\left(\mathrm{HFA}_{t}\right)$ for cortical gray matter areas (frontal, parietal, temporal, and occipital) in both hemispheres. The correlation coefficient or the rate of increase in heterogeneity with age is maximal in frontal and decreases in parietal, occipital, and temporal lobes in that order (correlation decreases from yellow to red). [Color figure can be viewed in the online issue, which is available at wileyonlinelibrary.com.] 

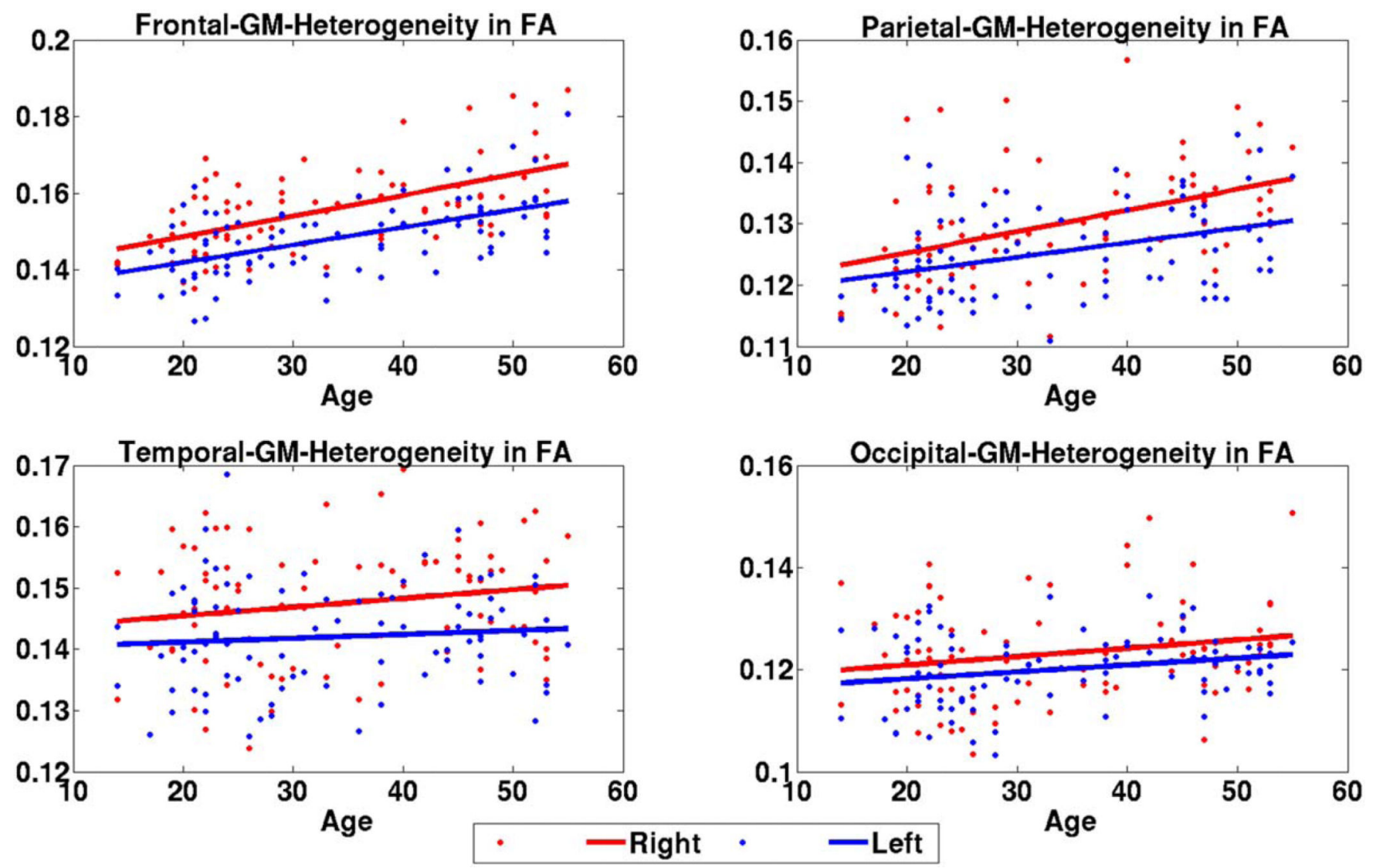

Figure 4.

Correlation between age and $\mathrm{HFA}_{\mathrm{t}}$ in the gray matter (GM) of the four anatomical lobes of both the hemispheres (right hemisphere-red, left hemisphere-blue). The correlation is highest and statistically significant $(P<0.001)$ in the frontal lobe followed by the parietal lobe. Not much statistically significant correlation is seen in the temporal and occipital lobes, indicating very little change in heterogeneity in early aging. [Color figure can be viewed in the online issue, which is available at wileyonlinelibrary.com.] 

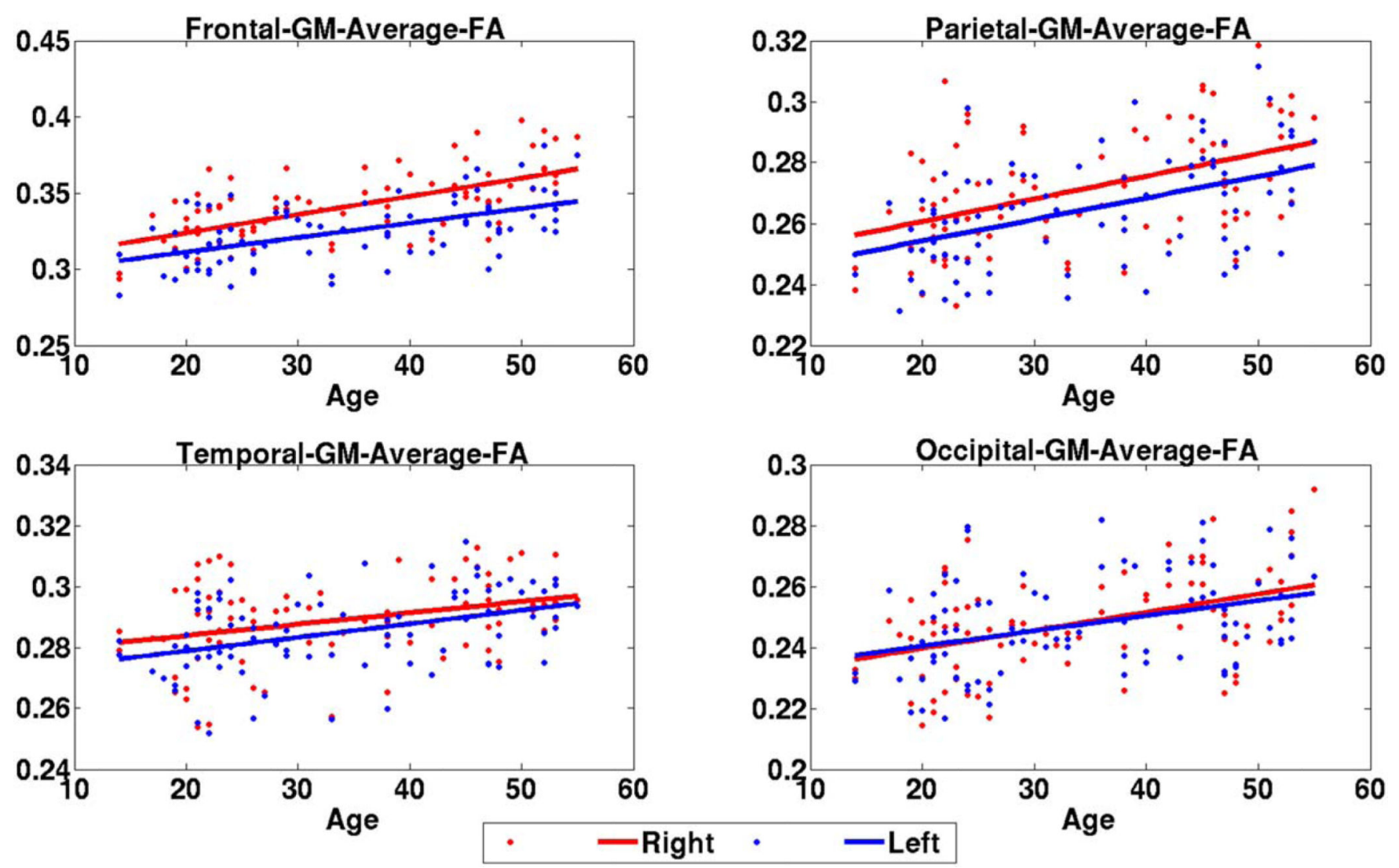

Figure 5.

Statistically significant $(P<0.001)$ correlation is seen between age and average $\mathrm{FA}_{\mathrm{t}}$ for all the four lobes in both hemispheres. The correlation is maximal in the frontal lobe followed by parietal, occipital, and temporal lobes in that order. [Color figure can be viewed in the online issue, which is available at wileyonlinelibrary.com.] 

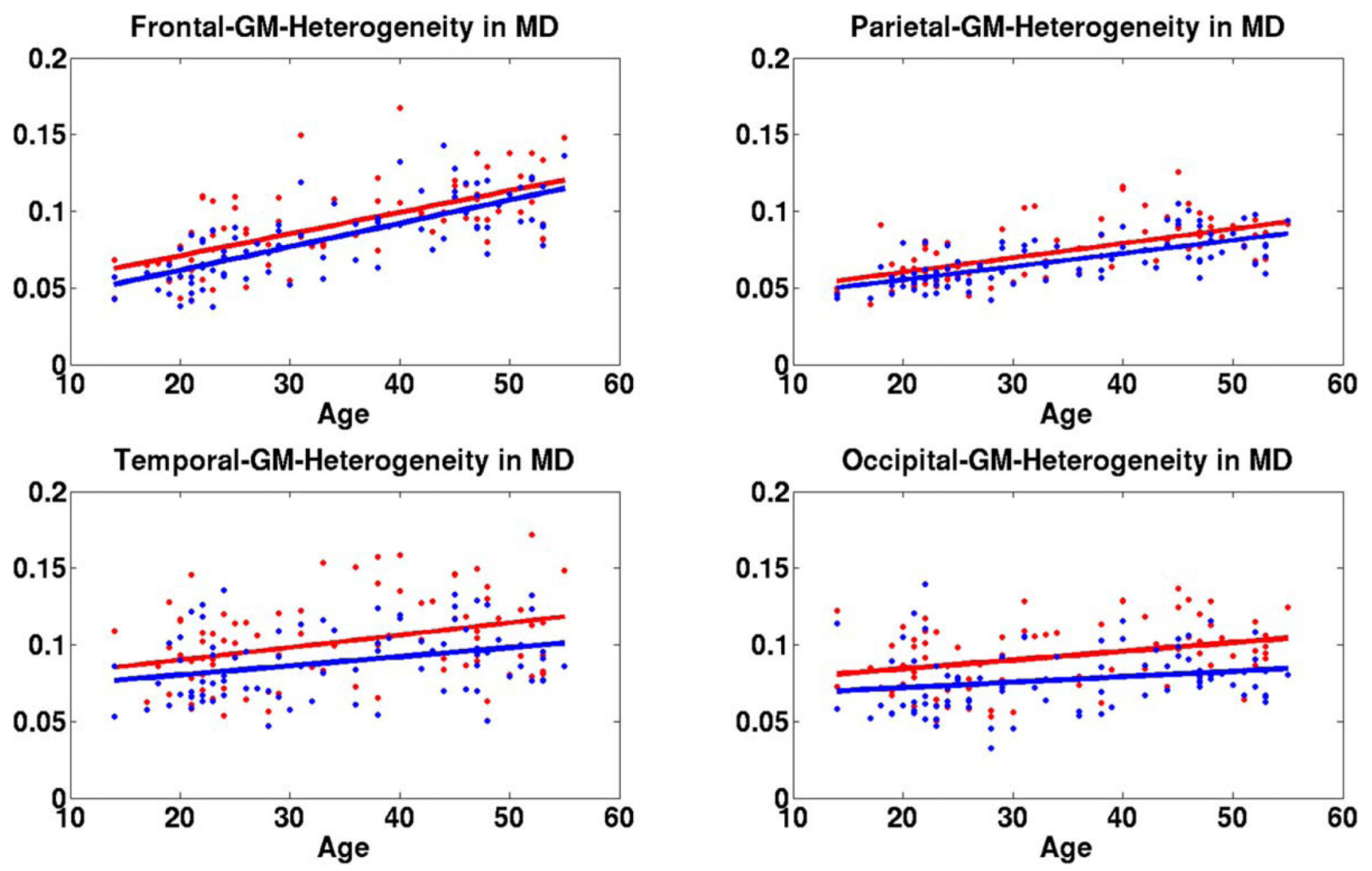

Figure 6.

Correlation between age and $\mathrm{HMD}_{\mathrm{t}}\left(\mathrm{mm}^{2} / \mathrm{s}\right)$ in the gray matter of the four anatomical lobes of both the hemispheres (right hemisphere—red, left hemisphere-blue). The correlation is statistically significant $(P<0.001)$ only for frontal and parietal lobe. No statistically significant correlation is seen in the temporal and occipital lobes. [Color figure can be viewed in the online issue, which is available at wileyonlinelibrary.com.] 


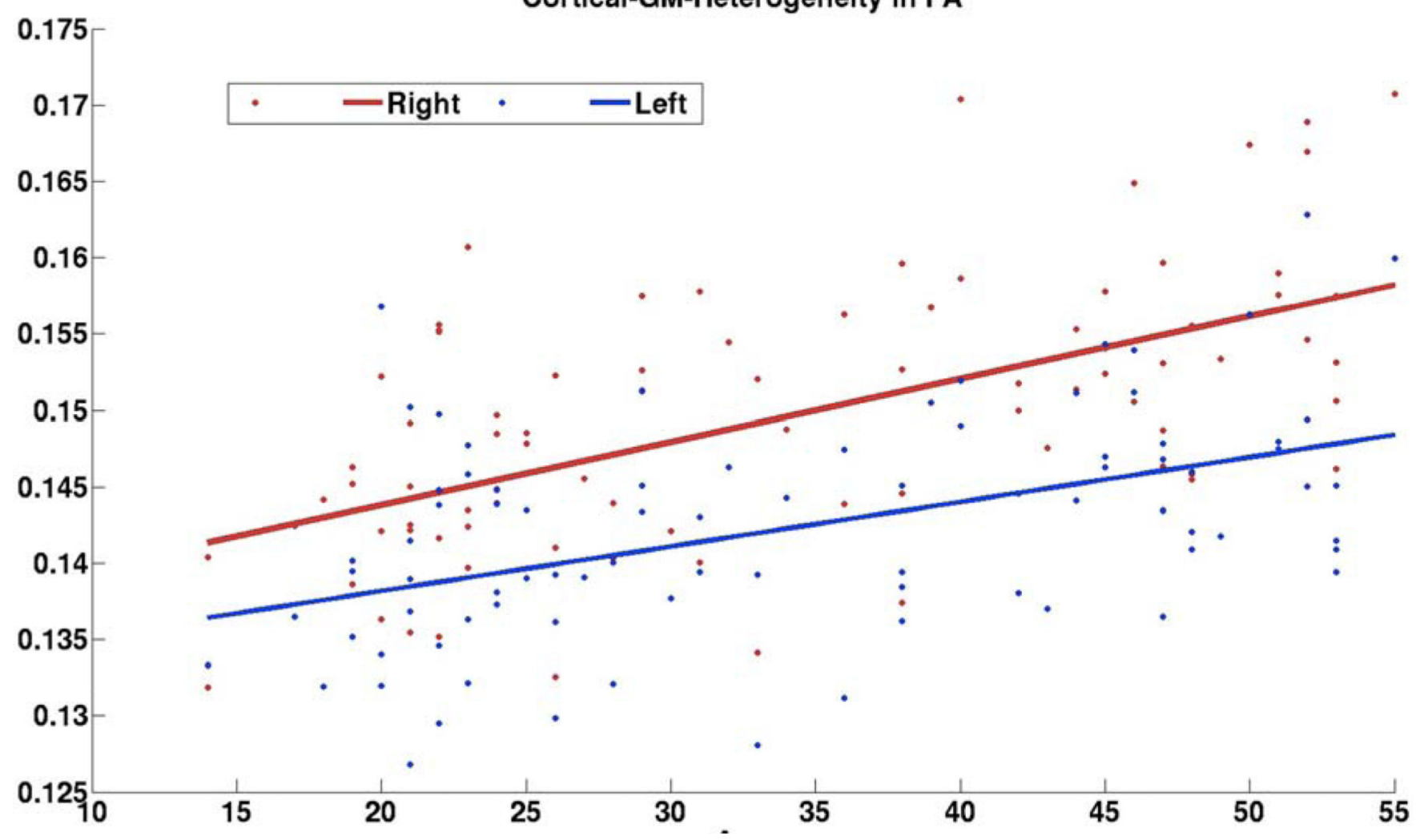

Figure 7.

Cortical (right and left) gray matter heterogeneity in FAt increases with age. Further, the increase in HFAt in the right hemisphere is more pronounced than the left. Notice that the right hemisphere starts with a higher value of heterogeneity at an early age. [Color figure can be viewed in the online issue, which is available at wileyonlinelibrary.com.] 


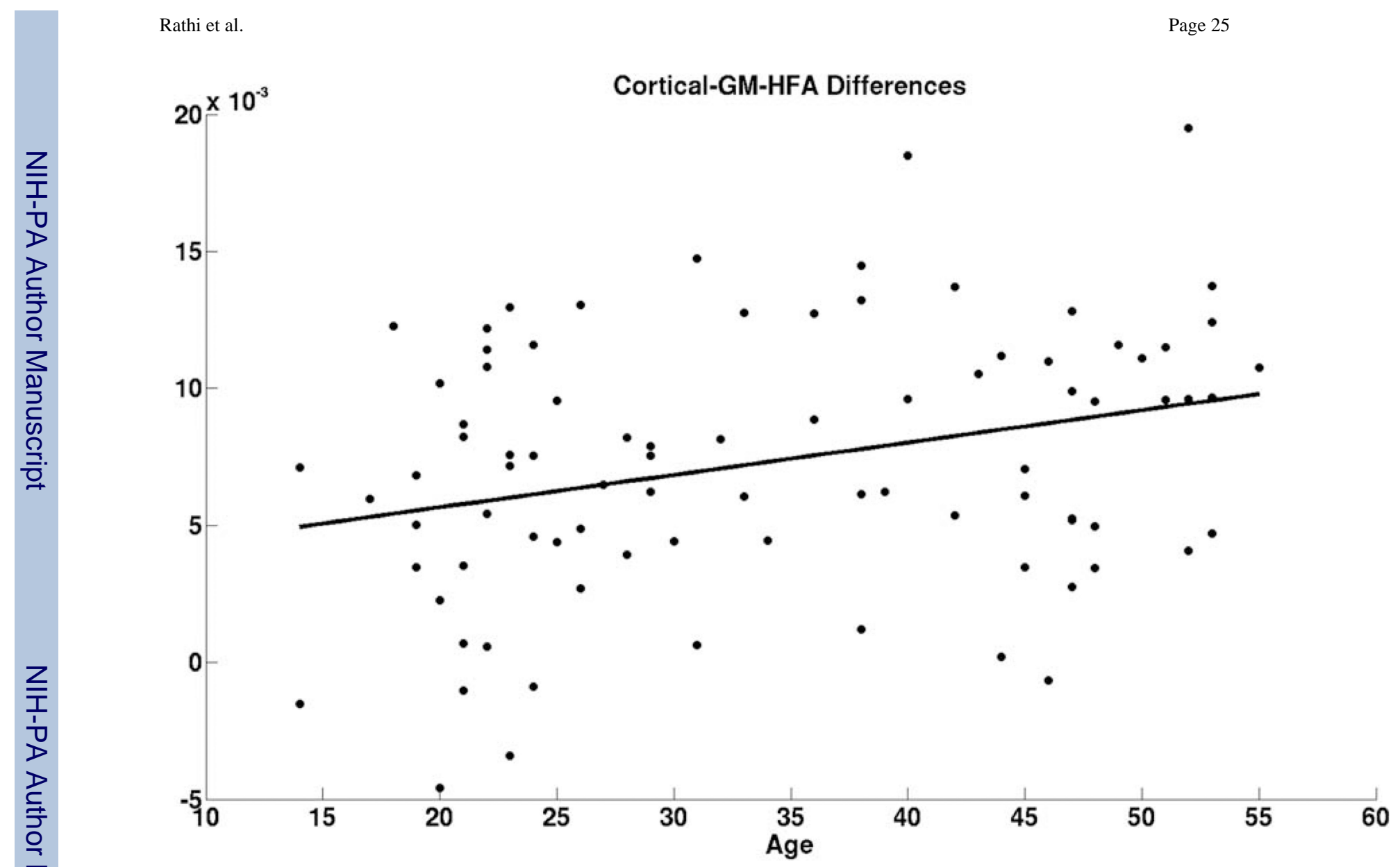

Figure 8.

Cortical hemispheric differences in heterogeneity (HFAt) increase with age $(P=0.005)$. 

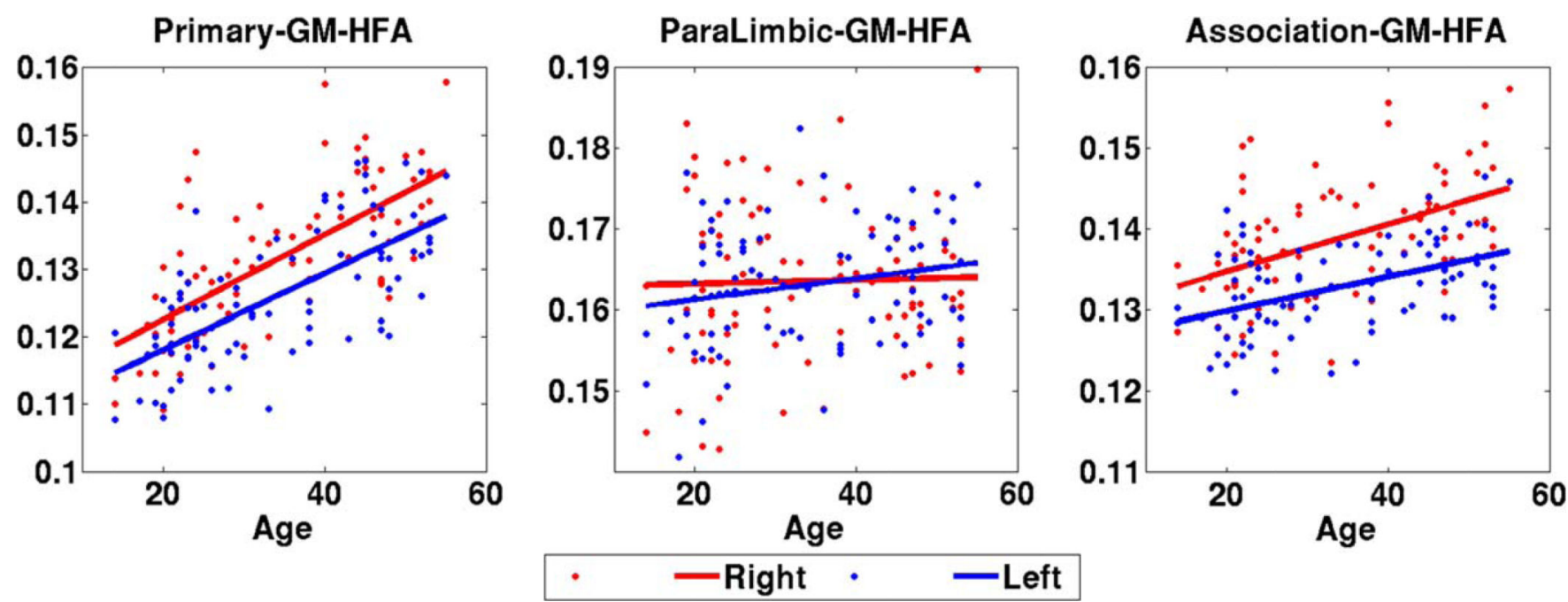

Figure 9.

Cortical gray matter heterogeneity (HFAt) in the three functional zones (primary, paralimbic, and association-left to right) for both the hemispheres. Statistically significant increase can be seen in the primary and the association zones, but not in the paralimbic areas. [Color figure can be viewed in the online issue, which is available at wileyonlinelibrary.com.] 

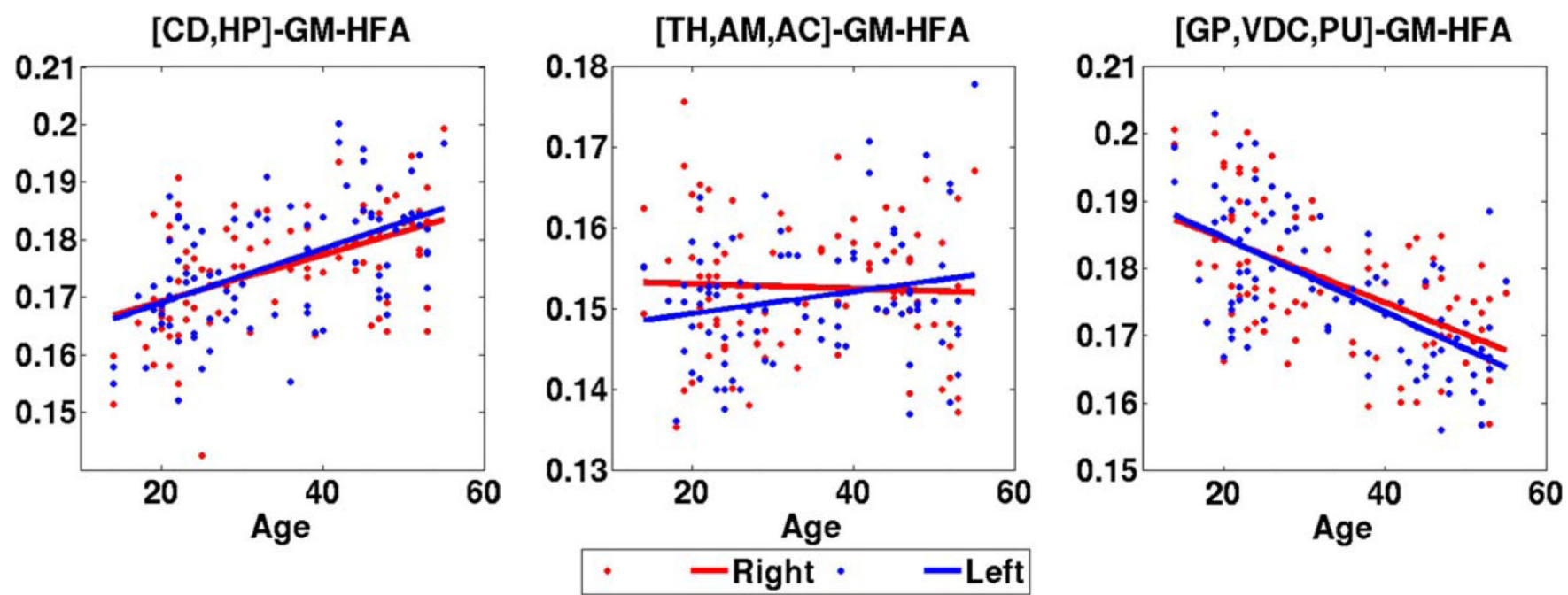

Figure 10.

Heterogeneity in FAt (HFAt) in the sub-cortical regions grouped according to whether HFAt increases, decreases, or remains unchanged. Combined plots are shown for the grouped regions. Significant increase is seen the caudate (CD) and hippocampus (HP), significant decrease is seen in globus pallidus (GP), ventral DC (VDC), and putamen (PU), while no change is observed in the thalamus (TH), amygdala (AM), and nucleus accumbens (AC) areas. [Color figure can be viewed in the online issue, which is available at wileyonlinelibrary.com.] 

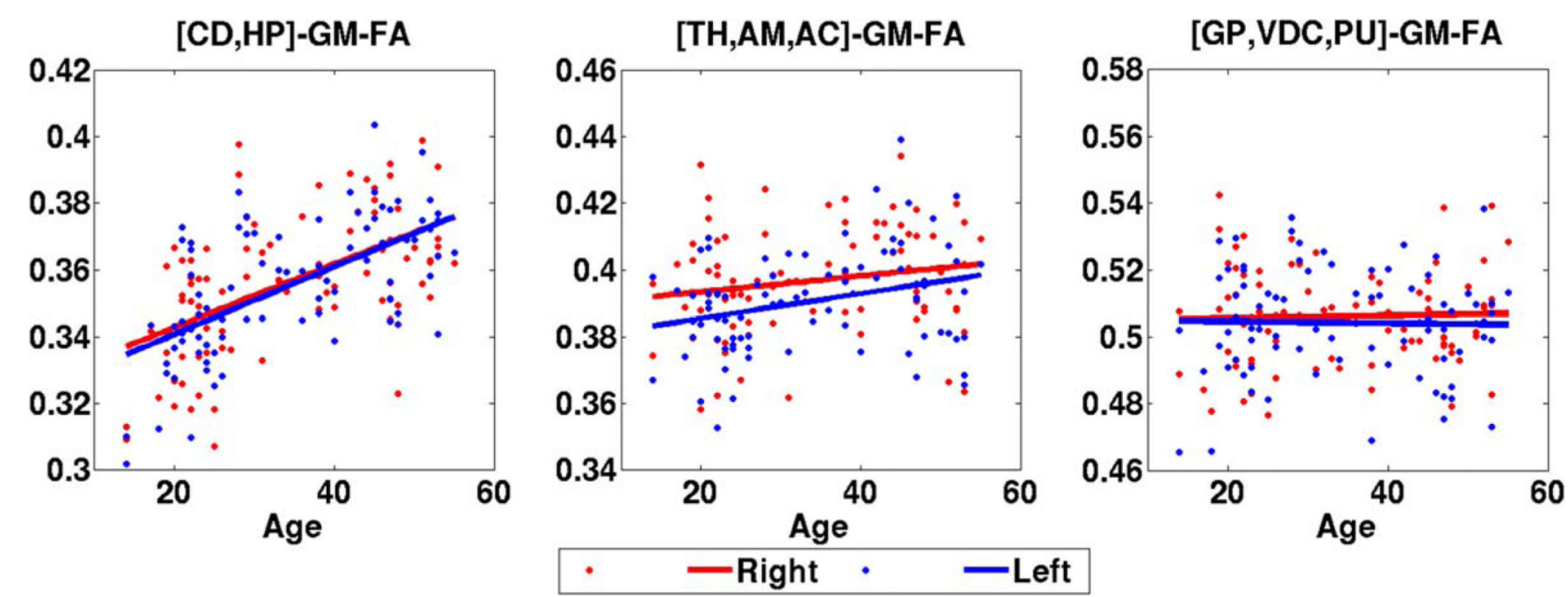

Figure 11.

Average FAt in the sub-cortical regions, grouped as described in Figure 7. A sharp increase in FAt $\left(P=10^{-11}\right)$ is seen in the caudate (CD) and hippocampus (HP), but only a minor increase is seen in the left amygdala (AM), with no change in the thalamus or accumbens areas (in either hemispheres). Also, no correlation is seen in the GP, VDC, and PU areas, even though HFAt decreases significantly in these regions. [Color figure can be viewed in the online issue, which is available at wileyonlinelibrary.com.] 
Hippocampus-GM-HFA

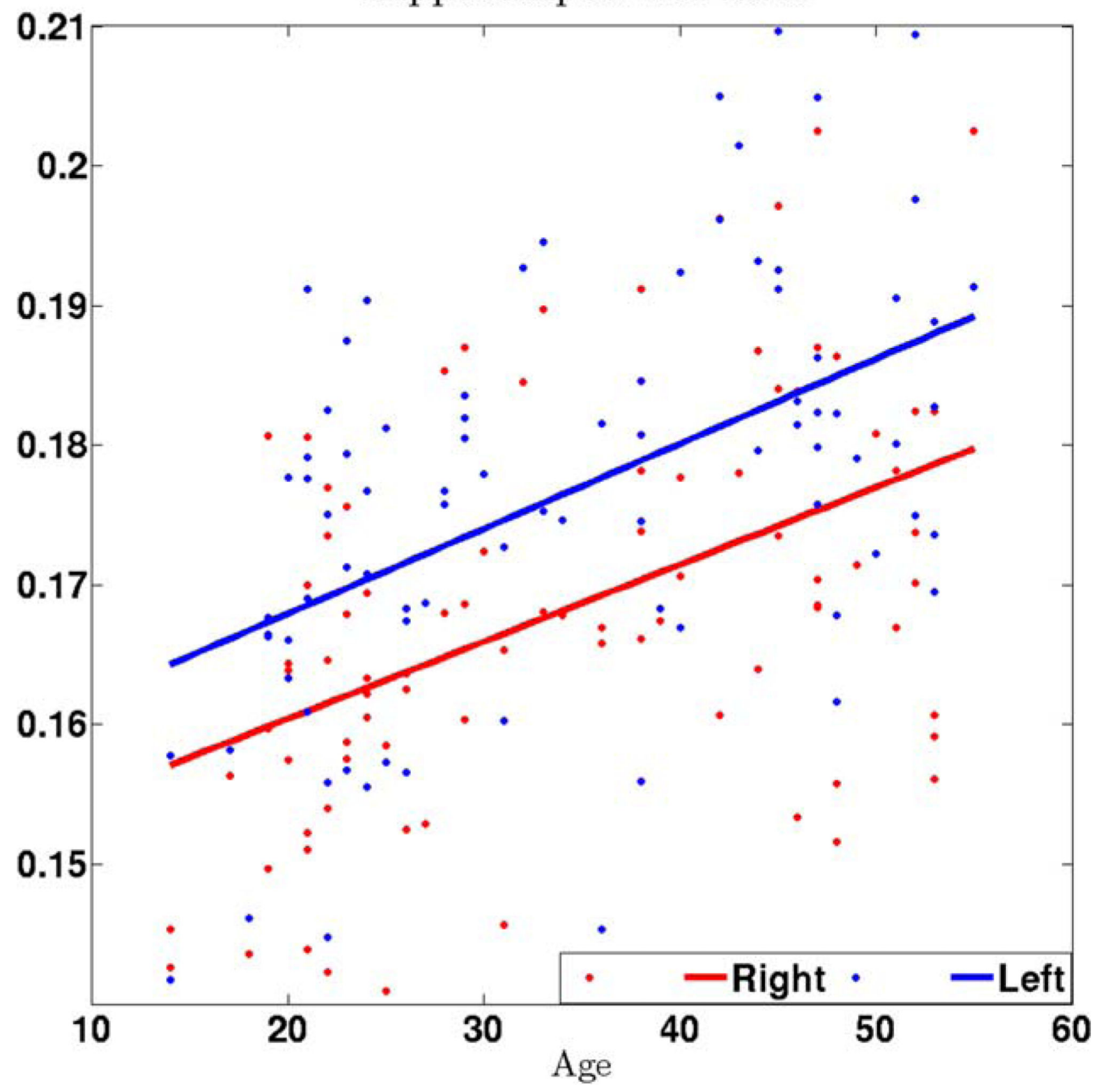

Figure 12.

HFA $_{\mathrm{t}}$ increases in hippocampus significantly $(P<0.001)$ with age in both hemispheres.

[Color figure can be viewed in the online issue, which is available at wileyonlinelibrary.com.] 

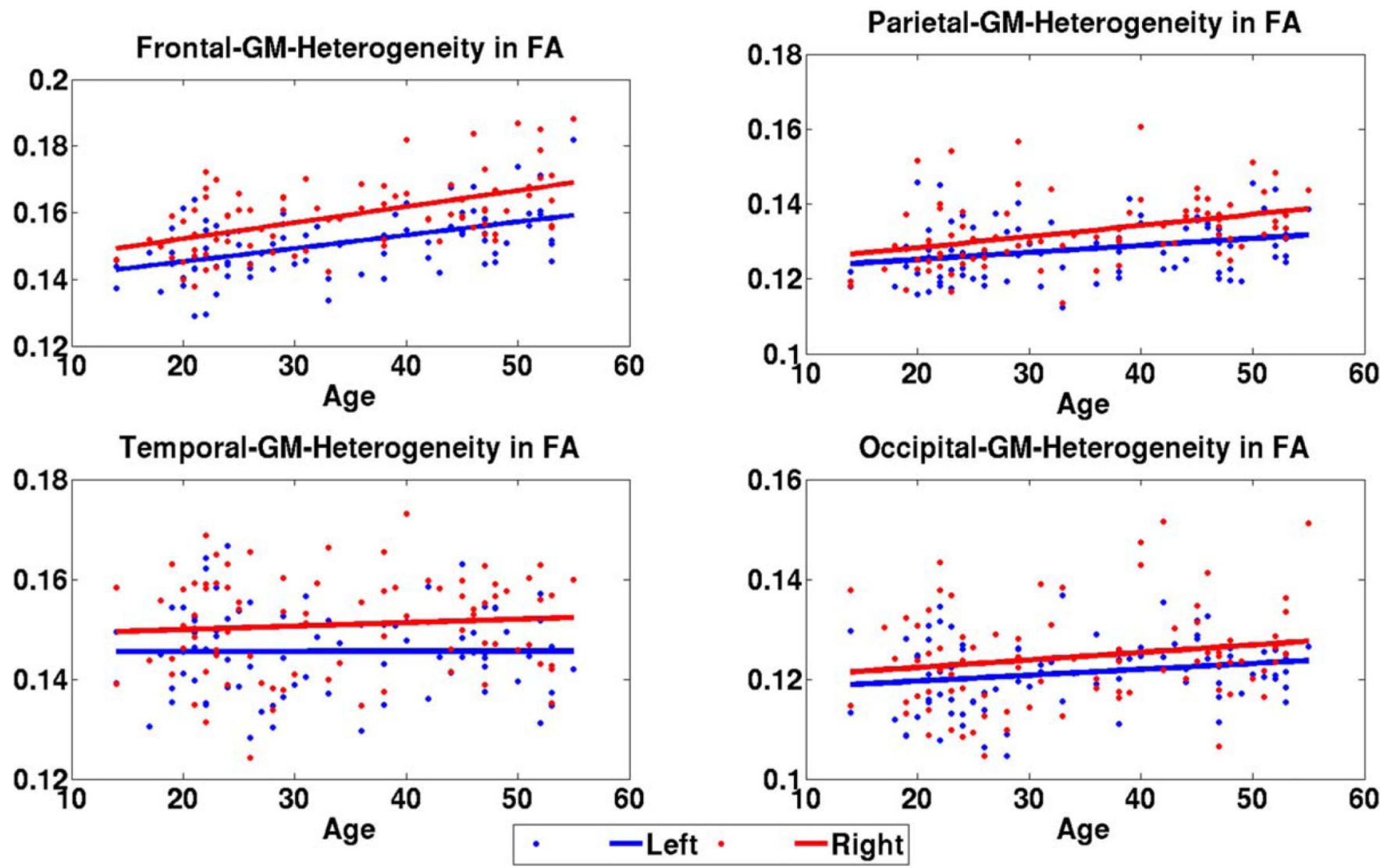

Figure 13.

Heterogeneity (HFAt) computed in all the four lobes frontal, parietal, temporal, and occipital with gray-white boundary voxels removed. HFAt increases similar to that in Figure 4 with statistically significant increase seen in the frontal and parietal lobes, but no increase in temporal and occipital lobes. [Color figure can be viewed in the online issue, which is available at wileyonlinelibrary.com.] 
TABLE I

Correlation coefficient for heterogeneity in $\mathrm{FA}_{t}\left(\mathrm{HFA}_{t}\right)$ and average $\mathrm{FA}_{\mathrm{t}}$

\begin{tabular}{lcccc}
\hline & Left HFA & Right HFA $_{\mathbf{t}}$ & Left FA & Right FA $_{\mathbf{t}}$ \\
\hline Frontal & $0.57^{a}$ & $0.60^{a}$ & $0.57^{a}$ & $0.64^{a}$ \\
Parietal & $0.39^{a}$ & $0.48^{a}$ & $0.49^{a}$ & $0.50^{a}$ \\
Occipital & 0.20 & 0.18 & $0.38^{a}$ & $0.44^{a}$ \\
Temporal & 0.10 & 0.16 & $0.40^{a}$ & $0.34^{a}$ \\
\hline
\end{tabular}

${ }^{a}$ Indicates statistically significant correlation with $P<0.001$. 
TABLE II

Correlation coefficient for heterogeneity in $\mathrm{MD}_{t}\left(\mathrm{HMD}_{t}\right)$ and average $\mathrm{MD}_{\mathrm{t}}$

\begin{tabular}{lcccc}
\hline & Left HMD & Right $_{\mathbf{t}} \mathbf{M D}_{\mathbf{t}}$ & Left $_{\mathbf{M D}}$ & Right $\mathbf{M D}_{\mathbf{t}}$ \\
\hline Frontal & $0.74^{a}$ & $0.65^{a}$ & $0.60^{a}$ & $0.54^{a}$ \\
Parietal & $0.66^{a}$ & $0.62^{a}$ & 0.23 & 0.09 \\
Occipital & 0.21 & 0.31 & 0.02 & 0.17 \\
Temporal & 0.31 & 0.34 & $0.39^{a}$ & 0.18 \\
\hline
\end{tabular}

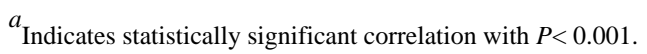




\section{TABLE III}

Correlation coefficient for the three functional zones

\begin{tabular}{lcccc}
\hline & Left HFA & Right HFA $_{\mathbf{t}}$ & Left FA $_{\mathbf{t}}$ & Right FA $_{\mathbf{t}}$ \\
\hline Primary & $0.69^{a}$ & $0.70^{a}$ & $0.64^{a}$ & $0.63^{a}$ \\
Paralimbic & 0.20 & 0.03 & $0.38^{a}$ & $0.39^{a}$ \\
Association & $0.46^{a}$ & $0.48^{a}$ & $0.55^{a}$ & $0.58^{a}$ \\
\hline \multicolumn{5}{l}{ Indicates statistically significant correlation with $P<0.001}$.
\end{tabular}

Hum Brain Mapp. Author manuscript; available in PMC 2014 August 01. 


\section{TABLE IV}

Correlation with age in the sub-cortical regions

\begin{tabular}{lcccc}
\hline Regions & Left HFA $_{\mathbf{t}}$ & Right HFA $_{\mathbf{t}}$ & Left FA & Right $_{\mathbf{F A}}$ \\
\hline CD, HP & $0.52^{a}$ & $0.48^{a}$ & $0.61^{a}$ & $0.54^{a}$ \\
TH, AM, AC & 0.21 & -0.04 & $0.29^{b}$ & 0.18 \\
GP, VDC, PU & $-0.63^{a}$ & $-0.55^{a}$ & -0.01 & 0.03 \\
\hline
\end{tabular}

$a_{\text {Indicates } P<0.001 \text {. }}$

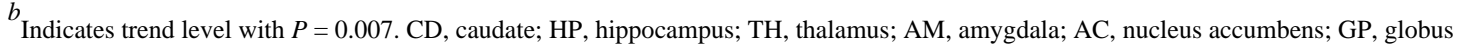
pallidus; VDC, ventral DC; PU, putamen. 


\section{TABLE V}

Correlation coefficient for heterogeneity in $\mathrm{FA}_{\mathrm{t}}\left(\mathrm{HFA}_{\mathrm{t}}\right)$ and average $\mathrm{FA}_{\mathrm{t}}$ with gray-white boundary voxels removed to account for partial-volume effects

\begin{tabular}{lcccc}
\hline & Left HFA & Right $_{\mathbf{t}} \mathbf{F A} \mathbf{A}_{\mathbf{t}}$ & Left FA & Right $_{\mathbf{t}} \mathbf{A}_{\mathbf{t}}$ \\
\hline Frontal & $0.51^{a}$ & $0.54^{a}$ & $0.55^{a}$ & $0.62^{a}$ \\
Parietal & $0.29^{b}$ & $0.39^{a}$ & $0.46^{a}$ & $0.46^{a}$ \\
Occipital & 0.20 & 0.18 & $0.36^{a}$ & $0.43^{a}$ \\
Temporal & 0.001 & 0.08 & $0.39^{a}$ & $0.32^{a}$ \\
\hline
\end{tabular}

${ }^{a}$ Indicates statistically significant correlation with $P<0.001$.

${ }^{b}{ }_{P}=0.003$. 